\title{
REFORMA FINANCIERA Y LA RESPONSABILIDAD SOCIAL EMPRESARIAL EN EL SECTOR BANCARIO DE MÉXICO*
}

\author{
FINANCIAL REFORM AND CORPORATE SOCIAL \\ RESPONSIBILITY IN THE BANKING SECTOR OF MEXICO \\ RÉFORME FINANCIÈRE ET RESPONSABILITÉ SOCIALE \\ DANS LE SECTEUR BANCAIRE DU MEXIQUE
}

\author{
Edith Patricia BORBOA ÁlVAREZ** \\ Sheila Delhumeau RiverA**
}

\begin{abstract}
RESUMEN: En los últimos años ha aumentado la importancia de la responsabilidad social empresarial y se ha generado una expansión de las iniciativas y herramientas voluntarias para una evaluación y comunicación transparente del desempeño del sector bancario. Al respecto, el gobierno mexicano plantea la necesidad de definir una propuesta para ajustar su acción reguladora mediante una reforma financiera. El propósito de este texto es analizar la actual reforma financiera en términos de la responsabilidad social del sector bancario establecido en México. Las principales conclusiones del análisis demuestran convergencias entre las iniciativas, los principios y las dimensiones de la responsabilidad social con el contenido de la reforma financiera; sin embargo, aunque se ha avanzado significativamente en el sector bancario del país, todavía existen pendientes que resolver con respecto al papel del Estado en la economía.
\end{abstract}

Palabras clave: reforma financiera, responsabilidad social empresarial y sector bancario. de 2017.

Recibido el 15 de febrero de 2017 y aprobado para su publicación el 4 de septiembre

\footnotetext{
** Instituto Tecnológico de Sonora, México.

*** Universidad Autónoma de Baja California.
}

IS Revista Latinoamericana de Derecho Social Núm. 26, enero-junio de 2018, pp. 29-88 
ABSTRACT: In recent years the importance of corporate social responsibility has increased and there has been an expansion of initiatives and voluntary tools for a transparent evaluation and communication of the performance of the banking sector. In this regard, the Mexican government raises the need to define a proposal to adjust its regulatory action through a financial reform. The purpose of this text is to analyze the current financial reform in terms of social responsibility of the banking sector established in Mexico. The main conclusions of the analysis show convergences between the initiatives, principles and dimensions of social responsibility with the content of the financial reform; however, although significant progress has been made in the banking sector of the country, there are still outstanding issues regarding the role of the State in the economy.

Keywords: financial reform, corporate social responsibility and banking sector.

RÉSUMÉ: Au cours des dernières années, l'importance de la responsabilité sociale des entreprises a augmenté et l'expansion des initiatives et des outils volontaires pour une évaluation et une communication transparentes de la performance du secteur bancaire. À cet égard, le gouvernement mexicain soulève la nécessité de définir une proposition visant à ajuster son action réglementaire par une réforme financière. Le but de ce texte est d'analyser la réforme financière actuelle en matière de responsabilité sociale du secteur bancaire établie au Mexique. Les principales conclusions de l'analyse montrent les convergences entre les initiatives, les principes et les dimensions de la responsabilité sociale avec le contenu de la réforme financière; cependant, bien que des progrès importants aient été réalisés dans le secteur bancaire du pays, il existe encore des problèmes en suspens concernant le rôle de l'État dans l'économie.

Mots-clés: la réforme financière, la responsabilité sociale des entreprises et le secteur bancaire. 
SuMARIO: I. Introducción. II. Análisis teórico conceptual de la Responsabilidad Social. III. Análisis del sector bancario del país. IV. Reflexión Final.

V. Fuentes de investigación.

\section{INTRODUCCIÓN}

$\Psi$ 1 tema de la responsabilidad social empresarial (RSE) es observado desde múltiples grupos de interés (stakeholders), en relación al compromiso organizacional con el cuidado del medio ambiente, el apoyo a la sociedad y la implementación de estrategias para un desarrollo económico responsable.

En los últimos años se ha presentado una tendencia a nivel global que demanda que las empresas establezcan mecanismos para reportar sus contribuciones al aspecto social y esto no excluye al sistema financiero mexicano (SFM). Eso ha aumentado la importancia por la RSE y ha generado una expansión de las expectativas para establecer indicadores que permitan una evaluación y comunicación transparente del desempeño del sector bancario.

Por lo tanto, la banca en México se enfrenta a la presión de organizaciones sociales, sindicalistas, capital humano, clientes, accionistas, comunidad, intelectuales, autoridades gubernamentales y demás stakeholders, que les exigen responsabilidades que van más allá de lo usual, referidas a aspectos sociales, ambientales y de gobierno corporativo.

Sin embargo, aunque hasta el momento toda esa búsqueda de iniciativas y herramientas para la RSE entre diversos grupos y organismos, tanto nacionales como internacionales, han generado guías e indicadores voluntarios para fomentarla y supervisar sus alcances, todavía son pocos los bancos que las aplican como parte de su estrategia corporativa y no se ha identificado claramente la contribución social del sector bancario en comunidades mexicanas específicas.

Para el desempeño transparente y eficiente de los distintos actores del sector financiero, juegan un papel importante las distintas autoridades financieras que las dotan de derechos, obligaciones y reglas transparentes. Arrazate ${ }^{1}$ señala que la aplicación de la ley y el respeto al Estado de derecho, tiene una gran influencia en el comportamiento bancario. Esto se puede volver una ventaja

1 Arrazate-Hernández, R., "Responsabilidad social en el sector bancario: un estudio de caso", Revista de Administración y Organizaciones: Compromiso y Responsabilidad Social y Ambiental de las Organizaciones, vol. 2, núm. 24, 2010, p. 110. 
si existe un marco adecuado para la operación bancaria, donde prevalezca un SFM competitivo y una adecuada regulación tanto como una supervisión prudencial.

En la medida que la RSE supone la aparición de nuevos retos y oportunidades que afectan al sector bancario, el gobierno se plantea la necesidad de definir una propuesta política que si bien no le permitiría "regular" todo un modelo de gestión corporativa, sí sería útil para ajustar su acción reguladora a aquellos aspectos de la RSE que, en un momento dado y en función de las políticas diseñadas, puedan necesitar la intervención del Estado con mayor urgencia.

Con la intención de atender las principales necesidades del país, surge en el 2012 un acuerdo político denominado Pacto por México, con 11 reformas estructurales diseñadas bajo tres grandes objetivos nacionales: elevar la productividad; fortalecer y ampliar los derechos de los mexicanos; y afianzar el régimen democrático. Del primer objetivo se deriva la reforma financiera (RF), a través del decreto por el que se reforman, adicionan y derogan diversas disposiciones en materia financiera y se expide la Ley para Regular las Agrupaciones Financieras, publicada en el Diario Oficial de la Federación (DOF) el 9 de enero de 2014.

En ese sentido, el planteamiento del problema que abarca este estudio es que los corporativos bancarios establecidos en México aún tienen mucho por hacer para evidenciar niveles más altos de RSE y tanto el contenido como los resultados de la actual RF no contribuyen en gran medida para lograr mejores resultados. La hipótesis que se plantea en este trabajo, es que la citada reforma financiera no es la herramienta para lograr la mejora del desempeño bancario en términos de responsabilidad social empresarial. El enfoque de la investigación es de tipo cualitativo; se utilizan los métodos analítico y deductivo para su desarrollo, y se tiene como principal técnica la documental.

De esta manera, el objetivo de este texto es llevar a cabo un análisis sobre la actual RF en términos de Responsabilidad Social del sector bancario establecido en México. Para lograrlo, el ensayo se organiza en tres secciones: primeramente se describe un análisis teórico conceptual, en el que se revisan aspectos de la RSE y se hace énfasis en sus principales iniciativas voluntarias y herramientas; en la siguiente parte se analiza el sector bancario del país, las regulaciones al mismo y el contenido de la reciente RF mexicana; finalmente, se derivan las reflexiones de la convergencia entre la Responsabilidad Social y la Reforma Financiera. 


\section{ANÁLISIS TEÓRICO CONCEPTUAL DE LA RSE}

\section{Concepto de RSE}

De acuerdo con algunos autores, ${ }^{2}$ en la actualidad existen varios organismos multilaterales de carácter nacional e internacional que se encargan de delimitar el concepto teórico de la RSE, dentro de los más destacados se pueden citar a los siguientes:

La Comisión Europea la conceptualiza como un proceso integrador de aspectos medioambientales y sociales en la cultura de la empresa que trata de considerar interna y externamente prácticas socialmente responsables con respecto a los trabajadores, salud y seguridad, gestión del cambio, medio ambiente, incidiendo en el respeto de los derechos humanos. ${ }^{3}$

El Pacto Mundial de las Naciones Unidas provee un marco general para fomentar el crecimiento sustentable y la RSE e incorpora diez principios reconocidos por la comunidad internacional como universales en tratados y declaraciones oficiales, agrupados en cuatro áreas en las que se puede propiciar una globalización más justa e incluyente: los derechos humanos, las normas laborales, la protección del medio ambiente y la lucha contra la corrupción. ${ }^{4}$

Asimismo, la International Organization for Standarization (ISO) ${ }^{5}$ entiende la "responsabilidad" de una organización como el impacto de sus decisiones y actividades sobre la sociedad y el ambiente, por medio de un comportamiento ético y transparente que: es coherente con el desarrollo sostenible y el bienestar de la sociedad; tiene en cuenta las expectativas de las partes

2 Duque-Orozco, Yenni Viviana y Martínez-Barón, Deissy, "Responsabilidad Social Empresarial en la dimensión laboral: caso Bancolombia y BBVA", Revista Facultad de Ciencias Económicas: Investigación y Reflexión, Colombia, vol. XX, núm. 1, junio 2012, pp. 171-187; González, F. M. T. y Gutiérrez, R. P., "The Impact and Perception of Corporate Social Responsibility (CSR): Financial Sector Analysis in Spain”, vol. 40, núm, 1, 2012, pp. 14-24.

3 Comisión Europea, Corporate Social Responsibility (CSR), EC, 2011, disponible en: http:// ec.europa.eu/enterprise/policies/sustainable-business/corporate-social-responsibility/index_en.btm.

4 Red del Pacto Mundial de y en México A.C., Informe de actividades 2014, México, 2015, disponible en: http:// wmw.pactomundial.org.mx/ home/wpcontent/ uploads/2015/04/Informe_final.pdf.

5 Esta norma internacional se ha desarrollado a través de un enfoque de stakeholders, con la participación de expertos de más de 90 países y 40 organizaciones internacionales y regionales representativas, que están involucradas en diversos aspectos de la RSE. Estos especialistas procedían de seis grupos distintos de partes interesadas: consumidores; gobierno; industria; trabajadores; organizaciones no gubernamentales (ONG's) y servicios, apoyo, investigación, academia y otros. 
involucradas; cumple con las leyes aplicables y es consistente con las normas internacionales de comportamiento; además está integrada en toda la Organización y en sus relaciones. ${ }^{6}$

El Instituto Ethos, ${ }^{7}$ coincide que la RSE es el compromiso de las empresas por contribuir al desarrollo económico sostenible, trabajando con los empleados, sus familias, la comunidad local y la sociedad en general para mejorar su calidad de vida.

En esa misma línea, para el Centro Mexicano de Filantropía (Cemefi), ${ }^{8}$ la primera visión para comprender la función que cumple una compañía es asociarla a la obligación moral de devolverle a la sociedad parte de los beneficios que obtiene, lo que se traduce en el compromiso consciente y congruente de cumplir integralmente con la finalidad de la empresa, tanto en lo interno como en lo externo, considerando las expectativas económicas, sociales y ambientales de todos sus participantes, demostrando respeto por la gente, los valores éticos y la comunidad, así como por el medio ambiente, contribuyendo de este modo a la construcción del bien común.

La consideración de estas definiciones forman la base para la construcción del concepto de RSE que ha trascendido a la filantropía, dando paso a una concepción global, incluyente y dinámica, que para esta investigación se definió como: compromiso de la banca por su impacto en la sociedad, respetando la legislación aplicable y en plena colaboración con los stakeholders con los que se relaciona, al integrar las preocupaciones sociales, económicas, medioambientales, éticas y el respeto de los derechos humanos en sus operaciones.

\section{Los principios de RSE}

Cuando se ejerce la RSE, el objetivo global para una organización se transforma en maximizar su contribución al desarrollo sostenible. Si bien no existe

6 International Organization for Standarization, ISO 26000. Guía de Responsabilidad Social, IOS, 2010, disponible en: https:// wmw.iso.org/obp/ wi\#iso:std:iso:26000:ed-1:v1:es.

7 Instituto Ethos, Indicadores Ethos de Responsabilidad Social Empresarial 2011, São Paulo, Instituto Ethos, 2011, disponible en: http:// wmw1.ethos.org.br/EthosWeb/arquivo/0-A-bbe2011_Indic_ETHOS_ESP.pdf.

8 Centro Mexicano para la Filantropía, Guía de participación para el proceso de obtención del Distintivo ESR 2016 y Manual de uso de la aplicación para responder el cuestionario diagnóstico, México, Cemefi, 2015, disponible en: http://mmw.cemefi.org/esr/images/Guia\%20de\%20participacion\%20 Distintivo\%20ESR\%202016\%20y\%20manual\%20del\%20sistema.pdf. 
una lista exhaustiva de principios a seguir, se plantea que las organizaciones deberían respetar por lo menos los siete principios que se describen a continuación de acuerdo con ISO:?

a) Rendición de cuentas: toda compañía debería rendir cuentas ante las autoridades competentes por sus impactos en la sociedad, la economía y el medio ambiente, así como las acciones preventivas sobre efectos negativos involuntarios e imprevistos que puedan surgir. En el caso de la banca, también debería aceptar la vigilancia pública y promover una pronta respuesta ante cualquier observación de las autoridades financieras.

b) Transparencia: implica la costumbre de toda organización para revelar de forma clara, precisa y completa la información sobre las decisiones y actividades de las que son responsables, incluyendo sus impactos conocidos y probables sobre la sociedad y el medio ambiente. Además, con respecto al sector bancario, esta información debería estar fácilmente disponible y accesible para todos los stakeholders interesados en consultarla.

c) Comportamiento ético: el comportamiento de cualquier institución debe estar alineado a los valores de la honestidad, equidad e integridad; adicionalmente en relación a los bancos, deben regirse por una política organizacional ética y un gobierno corporativo más humano.

d) Respeto a los intereses de las partes involucradas: las empresas deberían respetar, considerar y responder a los intereses de sus stakeholders, así sean distintos a los propios. Si bien es cierto, los objetivos de un corporativo bancario responden principalmente a sus accionistas, existe un conjunto de partes interesadas que se ven afectadas por sus actividades, acciones y decisiones, por lo que tomar en cuenta dichas expectativas es condición básica para operar de manera legítima en el país donde se han establecido.

e) Respeto al principio de legalidad: es el reconocimiento de que ningún individuo u organización está por encima de la ley y de que los gobiernos están también sujetos a la ley y, por ende, no tienen la potestad de actuar por fuera de sus marcos. El respeto a este principio implica que todas las instituciones financieras deben cumplir con las leyes y regulaciones aplicables.

\footnotetext{
9 International Organization for Standarization, op. cit.
} 
f) Respeto a la norma internacional de comportamiento: las instituciones deberían esforzarse por respetar las normas internacionales, aun cuando la ley o su implementación no salvaguarden los aspectos ambientales y sociales. Hoy los bancos son — sobre todo— globales, y es muy frecuente que subcontraten servicios en países donde las leyes laborales son más laxas, además deben evitar ser cómplices en las actividades de otras empresas que no sean coherentes con la normatividad internacional de comportamiento socialmente responsable.

g) Respeto a los derechos humanos: toda organización debería respetar los derechos humanos y reconocer tanto su importancia como su universalidad. En particular, la banca debería promover el respeto de los derechos humanos en todos los países y culturas donde operan y evitar beneficiarse de situaciones donde la ley o su implementación no proporcionen la protección adecuada, ya sea por un vacío legal o por prácticas inadecuadas.

\section{Dimensiones de la RSE}

El Libro Verde publicado por la Comisión Europea, establece dos dimensiones generales sobre las áreas donde se puede aplicar la RSE denominadas: interna y externa: ${ }^{10}$

\section{A. Dimensión interna}

Contempla la empresa desde el interés social y, por lo tanto, tiene que ver con aspectos clave de la gestión de los recursos humanos y de seguridad laboral, la formación y desarrollo de los trabajadores, adaptación al Cambio, y la gestión del impacto ambiental así como de los recursos naturales.

\section{B. Dimensión externa}

Esta dimensión está referida a las relaciones de la empresa con sus agentes externos y abarca a un amplio abanico stakeholders con los que se relaciona en

10 Comisión Europea, Documentos de la Unión Europea, Libros Verdes, 2014, disponible en: http:/ / ec.europa.eu/green-papers/index_es.htm. 
su entorno social y ambiental en el sentido más amplio, tales como: las comunidades locales; los socios comerciales; los clientes y proveedores; la administración y autoridades públicas; organizaciones no gubernamentales (ONG’s); derechos humanos en sentido estricto y los problemas ecológicos mundiales.

Por otro lado, Arcas-Lario y Briones-Peñalver, ${ }^{11}$ así como De la CuestaGonzález et al. ${ }^{12}$ señalan tres dimensiones adicionales en las que se subdivide la RSE, que están relacionados con los ámbitos del desarrollo sostenible:

a) Dimensión económica. Un comportamiento responsable de la empresa desde el punto de vista económico implica que ésta debe crear valor para todos los stakeholders con los que se relaciona.

b) Dimensión social. Supone el acatamiento de las leyes, el respeto de las costumbres e implicarse en la vida política y cultural. Los dos primeros aspectos requieren que la empresa acepte los estándares legales y socioculturales de la sociedad en la que opera, mientras que el último supone un papel más activo de la empresa, adoptando iniciativas que mejoran el bienestar general de la sociedad.

c) Dimensión medioambiental. Una compañía debe procurar satisfacer las necesidades actuales de stakeholders sin comprometer las de las generaciones futuras, contribuyendo así al desarrollo sostenible.

Desde otra perspectiva, Vargas-Sánchez y Vaca-Acosta ${ }^{13}$ señalan cuatro dimensiones en la RSE: 1) económica o responsabilidad de la empresa que se deriva de la producción de bienes y servicios con el fin de obtener un beneficio; 2) legal, en cuanto que las empresas han de desarrollar su actividad cumpliendo las regulaciones existentes; 3) ética, puesto que la empresa puede desarrollar actividades o prácticas que, aunque no son exigibles por la ley, son juzgadas como correctas por la sociedad, y 4) discrecional, al ha-

11 Arcas-Lario, Narciso y Briones-Peñalver, Antonio Juan, "Responsabilidad social empresarial de las organizaciones de la economía social. Valoración de la misma en las empresas de la región de Murcia", Revista de Economía Pública, Social y Cooperativa, España, vol. 65, núm. 1, 2009, pp. 143-161.

12 De la Cuesta-González, Marta et al., "Analysis of Social Performance in the Spanish Financial Industry Through Public Data. A Proposal”, Journal of Business Ethics, núm. 69, 2006, pp. 289-304.

13 Vargas-Sánchez, Alfonso y Vaca-Acosta, Rosa María, "Responsabilidad Social Corporativa y cooperativismo: vínculos y potencialidades", Revista de Economía Pública, Social y Cooperativa, CIRIEC, España, núm. 53, noviembre de 2005, pp. 261-283. 
cerse eco la empresa de actividades que, aunque no son una exigencia de la sociedad, sean satisfactorias.

\section{Iniciativas voluntarias y herramientas para la RSE}

Para esta investigación se recopiló información sobre las más conocidas iniciativas voluntarias y herramientas de RSE, nacionales e internacionales, aceptadas para aplicarse en instituciones financieras y el sector bancario de México. Como se mencionó en líneas anteriores, se obtuvo información del Distintivo de Empresa Socialmente Responsable (ESR) del Cemefi por ser el más reconocido en nuestro país, y en la parte internacional se seleccionan las líneas Directrices de la Organización para la Cooperación y el Desarrollo Económico (OCDE), los indicadores de desempeño del Global Reporting Initiative (GRI), la norma International Organization for Standarization (ISO) 26000, los Indicadores Ethos y los principios del Pacto Mundial.

\section{A. Lineas Directrices de la OCDE}

Estas líneas Directrices en responsabilidad social para empresas multinacionales (en adelante Directrices), parten de la OCDE; fundada en 1961 cuya misión es construir economías sólidas en sus países miembros, mejorar la eficiencia, los sistemas de mercado nacionales, ampliar el libre comercio y contribuir al desarrollo tanto en países industrializados como en desarrollo. ${ }^{14}$

Actualmente las Directrices son aplicables a todo tipo y tamaño de organizaciones, inclusive el sector bancario y en especial los bancos globales, por sus principios y estándares multilaterales apoyados gubernamentalmente que buscan fomentar una conducta empresarial responsable en todo el mundo y están respaldadas por un mecanismo de implementación denominado Puntos Nacionales de Contacto (PNC), que son organismos constituidos por los gobiernos de los países adherentes con el fin de promoverlas e implementarlas.

La OCDE, propone estas Directrices a sus países miembros para su aplicación empresarial, con la creación de los Puntos Nacionales de Contacto

14 Organización para la Cooperación y el Desarrollo Económico, Importancia de una conducta responsable para las empresas, 2013, disponible en: https://mneguidelines.oecd.org/MNEguidelines_RBCmatters_ES.pdf. 
Esta revista forma parte del acervo de la Biblioteca Jurídica Virtual del Instituto de Investigaciones Jurídicas de la UNAM http://www.juridicas.unam.mx/

(PNC), que son organismos constituidos por los gobiernos de los países adherentes con el fin de promoverlas e implementarlas. ${ }^{15}$

La figura 1 muestra los componentes de las Directrices que debe atender el sector bancario y se refieren al trato nacional, las obligaciones impuestas, a los incentivos o desincentivos para la inversión internacional, ya que las actividades de la banca extranjera se han fortalecido, trasladando importantes beneficios tanto para sus países de origen como nuestro país en su rol de anfitrión.

\section{FigURA 1. LÍNEAS DIRECTRICES OCDE}

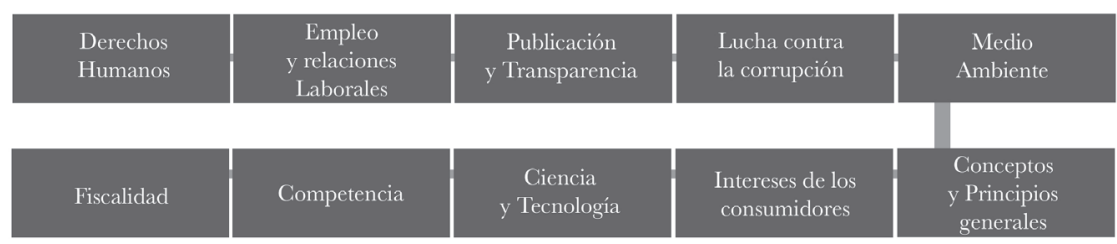

FUENTE: Elaboración propia a partir de Organización para la Cooperación y el Desarrollo Económico, Importancia de una conducta responsable para las empresas, 2013, disponible en: https:// mneguidelines.oecd.org/MNEguidelines_RBCmatters_ES.pdf.

Actualmente las organizaciones bancarias se enfrentan a una gran variedad de marcos legales y normativas sociales, por lo que podrían verse tentadas a descuidarlos con el fin de obtener una ventaja competitiva indebida, lo que aumenta la preocupación de los stakeholders por la responsabilidad de sus prácticas. Además pueden utilizar sistemas de gestión responsable que avalen su compromiso de buena ciudadanía corporativa, respeto de las buenas prácticas y buena conducta empresarial. ${ }^{16}$

Uno de los objetivos más importantes que persiguen las Directrices y que atañen al sector bancario es facilitar la comprensión de sus actividades y su interacción con los stakeholders, por lo que es necesario que actúen con transparencia y establezcan una comunicación adecuada con ellos. Este

15 Los 34 países miembros de la OCDE son: Alemania, Australia, Austria, Bélgica, Canadá, Chile, Corea, Dinamarca, Eslovenia, España, Estados Unidos, Estonia, Finlandia, Francia, Grecia, Hungría, Irlanda, Islandia, Israel, Italia, Japón, Luxemburgo, Noruega, Nueva Zelanda, Países Bajos, Polonia, Portugal, Reino Unido, República Checa, República Eslovaca, Suecia, Suiza, Turquía y México. Además, 12 países no miembros han firmado la implementación de las Directrices: Argentina, Brasil, Colombia, Costa Rica, Egipto, Jordania, Letonia, Lituania, Marruecos, Perú, Rumania y Túnez (idem).

16 Ibidem, p. 17. 
rubro se relaciona con la publicación de información de la banca en forma y plazo oportuno, no solamente sobre sus resultados financieros, sino integrando datos sobre sus políticas de remuneración y designación del consejo, transacciones con partes vinculadas, riesgos previsibles, estadísticas y porcentajes sobre participaciones sociales y campañas realizadas, de una forma más completa, además de lo solicitado por la Comisión Nacional Bancaria y de Valores (CNBV), la Secretaría de Hacienda y Crédito Público o cualquier otra autoridad financiera nacional o internacional.

Como parte de esta integración, Aranguren-Gómez y Martínez-Cerna incluyen la problemática de la transparencia informativa que puede relacionarse con la actividad bancaria. ${ }^{17}$ Así, la rendición de cuentas como mecanismo de divulgación puede buscar, por un lado, mantener informados a los stakeholders sobre las actuaciones responsables de la banca y, por otro, legitimarla frente al mercado. Una herramienta útil se deriva de la actual RF que exige a las instituciones bancarias del país que presenten una evaluación anual para reportar su desempeño y mostrarle a la sociedad mexicana si éste es satisfactorio o no lo es.

En relación a los intereses de los consumidores es importante que los bancos tengan en cuenta las necesidades específicas de los clientes más vulnerables o desfavorecidos, los problemas específicos del comercio electrónico, resolución de conflictos, difusión y validez de información financiera para que los usuarios puedan tomar mejores decisiones, la protección de los datos de carácter personal y toda aquella lucha contra las prácticas engañosas en la dinámica bancaria. ${ }^{18}$

Para la OCDE, ${ }^{19}$ la consecución del desarrollo sostenible se considera que la contribución de las empresas a las finanzas públicas de los países de acogida, no sólo se debe cumplir con la normativa fiscal correspondiente, sino también respetar la jurisprudencia existente y una colaboración mutua equilibrada incluyendo la nueva reforma financiera promulgada en enero de 2014.

17 Aranguren-Gómez, Nagore y Martínez-Cerna, Luis, "Divulgación de información sobre responsabilidad social por los bancos chilenos: una aproximación desde la teoría de la legitimidad”, Economía Global e Gestão, vol. 15, núm. 2, 2010, pp. 115-135.

18 Organización para la Cooperación y el Desarrollo Económico, op. cit.

19 Ibidem, p. 18. 


\section{B. Memorias o informes del Global Reporting Initiative (GRI)}

En lo que se refiere a las memorias o informes de sostenibilidad, Delgado $^{20}$ destaca que la iniciativa internacional más estandarizada es el GRI ${ }^{21}$ que surge con la idea de servir de marco aceptado para informar acerca del desempeño económico, ambiental y social (conocido como triple balance o triple bottom line) de las empresas con independencia de su tamaño, sector o localización. Esta iniciativa tiene amplia aceptación en el sector bancario, ya que algunos de los bancos establecidos en México la han adoptado como parte de sus objetivos organizacionales a cubrir año tras año, principalmente los globales.

La primera dimensión del triple balance, la cual forma parte de la propia misión de la banca, incluye el deber de reportar los informes financieros de la empresa entre otros aspectos, tales como salarios, productividad, creación de empleo, inversiones en investigación, desarrollo, innovación y capital humano.

La segunda dimensión es social, que incluye aspectos como la seguridad e higiene en el trabajo, la retención en el empleo, los derechos de los trabajadores, los salarios y las condiciones de trabajo también en las empresas subcontratadas.

La tercera dimensión es ambiental, la cual describe el impacto en el medio natural de la empresa e incluye la utilización de recursos materiales y energéticos, las emisiones a la atmósfera, los contaminantes, los residuos sólidos y los impactos ambientales en la salud humana.

\section{Principios del Pacto Mundial}

El Pacto Mundial es una iniciativa que data de 1999, en la que los participantes ingresan voluntariamente con el objetivo de proveer un marco general para fomentar el crecimiento sustentable y la RSE. Pueden intervenir en el

20 Delgado-Sierra, Virgilio, Estudio del grado de desarrollo de la responsabilidad social corporativa a través de las memorias de sostenibilidady de las audiencias en televisión, tesis de doctorado, España, Universidad de la Rioja, 2012, disponible en: http://biblioteca.universia.net/btml_bura/ficha/params/ id/56506493.html.

21 La Global Report Initiative fue creada en 1997 por la Unión de la Coalición de Economías Responsables del Medio Ambiente (CERES) y el Programa de Medio Ambiente de las Naciones Unidas (PNUMA). 
mismo: los gobiernos, las compañías y sus trabajadores, beneficiando a las localidades en la medida que hay empresas socialmente responsables. ${ }^{22}$

$\mathrm{Al}$ apoyar el Pacto Mundial, los participantes deciden incorporarse a una red de empresas empeñadas en mejorar las prácticas comerciales, en cuatro áreas en las que se puede propiciar una globalización más justa e incluyente: los derechos humanos, las normas laborales, la protección del medio ambiente y la lucha contra la corrupción. En la tabla 1 se transcriben los diez principios propuestos por la Red del Pacto Mundial relacionándolos con el área a la que se vinculan, los cuales son reconocidos por la comunidad internacional que integra la organización como universales en tratados y declaraciones oficiales. ${ }^{23}$

\section{TABLA 1. PRINCIPIOS DEL PACTO MUNDIAL}

\begin{tabular}{|c|l|c|}
\hline Núm. & \multicolumn{1}{|c|}{ Principio } & \multicolumn{1}{|c|}{ Área } \\
\hline 1 & $\begin{array}{l}\text { Las empresas deben apoyar y respetar la protección de los } \\
\text { derechos humanos reconocidos universalmente, dentro de su } \\
\text { ámbito de influencia. }\end{array}$ & 1. Derechos \\
Humanos
\end{tabular}

22 Red del Pacto Mundial de y en México A.C., Informe de actividades 2012 y 2013, México, 2014, disponible en: https://dl.dropboxusercontent.com/u/65975967/PMM/2014/Informe_2012_2013/IPMM2013_ok_FINAL.pdf.

23 Red del Pacto Mundial de y en México A.C., Informe de actividades 2014, México, 2015, disponible en: http:/ / wnw.pactomundial.org.mx/ home/ wpcontent/ uploads/2015/04/Informe_final.pdf. 
Esta revista forma parte del acervo de la Biblioteca Jurídica Virtual del Instituto de Investigaciones Jurídicas de la UNAM

\begin{tabular}{|c|l|l|}
\hline Núm. & \multicolumn{1}{|c|}{ Principio } & \multicolumn{1}{c|}{ Área } \\
\hline 10 & $\begin{array}{l}\text { Las empresas deben trabajar en contra de la corrupción en to- } \\
\text { das sus formas, incluidas la extorsión y el soborno. }\end{array}$ & $\begin{array}{l}\text { 4. Lucha contra } \\
\text { la corrupción }\end{array}$ \\
\hline
\end{tabular}

Fuente: Elaboración propia a partir de Red del Pacto Mundial de y en México A.C., Informe de actividades 2012 y 2013, México, 2014, disponible en: https://dl.dropboxusercontent. $\mathrm{com} /$ u/65975967/PMM/2014/Informe_2012_2013/IPMM2013_ok_FINAL.pdf.

\section{El Pacto Mundial en México}

México se unió a la Red del Pacto Mundial el 9 de junio del 2005, con el apoyo del Programa de las Naciones Unidas para el Desarrollo (PNUD) y la participación de más de 200 representantes de empresas y organizaciones mexicanas que se reunieron en el Polyforum Siqueiros de la Ciudad de México. Un año después, se hace la invitación a las empresas participantes de la iniciativa en el país a conformar el Comité del Pacto Mundial en México. Las organizaciones fundadoras son ASUR, Cruz Azul, Expok, Grupo Xcaret, Pricewaterhouse Coopers, Toks y Scotiabank México, el primer banco en integrarse, además el único que a febrero de 2016 es parte del comité ejecutivo liderando la comisión de dialogo y capacitación en México. ${ }^{24}$

En el 2011, la Red organiza el "VI Encuentro Anual de Redes Locales del Pacto Mundial de las Américas” y recibe a originarios de 10 países: Argentina, Brasil, Chile, Colombia, República Dominicana, Panamá, Paraguay, Perú, Uruguay y Estados Unidos. A principios del 2014, nuestro país se convierte en la red del Pacto Mundial más grande de América y la tercera en el mundo, después de España y Francia, rompiendo un récord histórico generando 220 Comunicaciones sobre el Progreso (CoP) en un año. ${ }^{25}$

Del 2009 al 2010 Scotiabank era la única institución financiera en México en ser parte del Pacto Mundial. Sin embargo, entre las 91 empresas adheridas, al 2011 se destacan dos empresas relacionadas con el sector de servicios financieros: el Grupo Financiero Banorte S.A.B. de C.V. y la Fundación BBVA Bancomer A.C.

\footnotetext{
24 Idem.

25 Idem.
} 
Para el 2012, año con el mayor número de adhesiones históricamente, se integra Financiera Rural (antes Banrural y a finales del 2013 cambia a Financiera Nacional de Desarrollo Agropecuario, Rural, Forestal y Pesquero) y el Grupo Financiero Santander en México. ${ }^{26}$ En el 2013 de las 158 adhesiones se resalta Fundación Quiera, de la Asociación de Bancos de México, A.C. y el Banco Nacional de México, S.A., mientras que de las 125 organizaciones sumadas al Pacto Mundial en el 2014, se resaltan las seis principales ordenadas por número de colaboradores: Grupo Bimbo S.A.B. de C.V., Teléfonos de México S.A.B. de C.V., Grupo Lamosa, S.A.B. de C.V., honorable Ayuntamiento del municipio de Durango y Banco del Bajío S.A. como institución de banca múltiple. ${ }^{27} \mathrm{El}$ crecimiento de adhesiones en el 2015 fue de 134 y 136 en el 2016.28

D. ISO 26000

Esta norma internacional se ha desarrollado utilizando un enfoque de stakeholders, con la participación de expertos de más de 90 países y 40 organizaciones internacionales y regionales representativas, que están involucradas en diversos aspectos de la RSE. Estos especialistas procedían de grupos distintos de partes interesadas: consumidores, gobierno, industria, trabajadores, organizaciones no gubernamentales y servicios, investigación y academia, entre otros. ${ }^{29}$

La ISO 26000 es un documento de orientación internacional sobre la RSE que proporciona a una organización de los principios y las materias básicas que debería estar implementando para garantizar que se identifiquen y gestionen los riesgos de impacto social. Abarca como áreas centrales: gobernabilidad organizacional, derechos humanos, prácticas laborales, medio ambiente, prácticas justas de operación, asuntos de consumidores, así como participación y desarrollo comunitario cada una con sus respectivos asuntos que atender (tabla 2).

26 Red del Pacto Mundial de y en México A.C., Informe de actividades 2012..., cit.

27 Red del Pacto Mundial de y en México A.C., Informe de actividades 2015..., cit.

28 Red del Pacto Mundial de y en México A.C., Informe de actividades 2016..., cit.

29 International Organization for Standarization, op. cit. 


\section{TABLA 2. MATERIAS FUNDAMENTALES Y ASUNTOS DE RESPONSABILIDAD SOCIAL}

\begin{tabular}{|c|c|}
\hline Materia fundamental & Asunto \\
\hline \multicolumn{2}{|l|}{ 1. Gobernanza de la organización } \\
\hline \multirow{8}{*}{ 2. Derechos humanos } & Debida diligencia. \\
\hline & Situaciones de riesgo para los derechos humanos. \\
\hline & Evitar la complicidad. \\
\hline & Resolución de reclamaciones. \\
\hline & Discriminación y grupos vulnerables. \\
\hline & Derechos civiles y políticos. \\
\hline & Derechos económicos, sociales y culturales. \\
\hline & Principios y derechos fundamentales en el trabajo. \\
\hline \multirow{5}{*}{ 3. Prácticas laborales } & Trabajo y relaciones laborales. \\
\hline & Condiciones de trabajo y protección social. \\
\hline & Diálogo social. \\
\hline & Salud y seguridad ocupacional. \\
\hline & $\begin{array}{l}\text { Desarrollo humano y formación en el lugar de tra- } \\
\text { bajo. }\end{array}$ \\
\hline \multirow{4}{*}{ 4. El medio ambiente } & Prevención de la contaminación. \\
\hline & Uso sostenible de los recursos. \\
\hline & Mitigación y adaptación al cambio climático. \\
\hline & $\begin{array}{l}\text { Protección del medio ambiente, la biodiversidad y } \\
\text { restauración de hábitats naturales. }\end{array}$ \\
\hline \multirow{5}{*}{ 5. Prácticas justas de operación } & Anticorrupción. \\
\hline & Participación política responsable. \\
\hline & Competencia justa. \\
\hline & $\begin{array}{l}\text { Promover la responsabilidad social en la cadena de } \\
\text { valor. }\end{array}$ \\
\hline & Respeto a los derechos de la propiedad. \\
\hline \multirow{4}{*}{ 6. Asuntos de consumidores } & $\begin{array}{l}\text { Prácticas justas de marketing, información objetiva } \\
\text { e imparcial y prácticas justas de contratación. }\end{array}$ \\
\hline & $\begin{array}{l}\text { Protección de la salud y la seguridad de los consu- } \\
\text { midores. }\end{array}$ \\
\hline & Consumo sostenible. \\
\hline & $\begin{array}{l}\text { Servicios de atención al cliente, apoyo y resolución } \\
\text { de quejas y controversias. }\end{array}$ \\
\hline
\end{tabular}


Esta revista forma parte del acervo de la Biblioteca Jurídica Virtual del Instituto de Investigaciones Jurídicas de la UNAM

\begin{tabular}{|l|l|}
\hline \multicolumn{1}{|c|}{ Materia fundamental } & \multicolumn{1}{c|}{ Asunto } \\
\hline \multirow{4}{*}{ 6. Asuntos de consumidores } & $\begin{array}{l}\text { Protección y privacidad de los datos de los consu- } \\
\text { midores. }\end{array}$ \\
\cline { 2 - 3 } & Acceso a servicios esenciales. \\
\cline { 2 - 3 } & Educación y toma de conciencia. \\
\hline \multirow{4}{*}{ 7. Participación activa y desarrollo de } & Participación activa de la comunidad. \\
\cline { 2 - 3 } & Educación y cultura. \\
\cline { 2 - 3 } & Creación de empleo y desarrollo de habilidades. \\
\cline { 2 - 3 } & Desarrollo y acceso a la tecnología. \\
\cline { 2 - 3 } & Generación de riqueza e ingresos. \\
\cline { 2 - 3 } & Salud. \\
\cline { 2 - 3 } & Inversión social. \\
\hline
\end{tabular}

FUENTE: Elaboración propia a partir de International Organization for Standarization, ISO 26000. Guia de Responsabilidad Social, 2010, disponible en: bttps://mmm.iso.org/obp/ ui\#iso:std:iso:26000:ed-1:v1:es.

\section{E. Indicadores Ethos de RSE}

El Instituto Ethos de Brasil actualmente tiene los indicadores de RSE como herramienta que ha ayudado a las empresas a incorporar en su gestión los conceptos y sus compromisos con la responsabilidad social y el desarrollo sostenible. Los indicadores están estructurados en forma de cuestionario para apoyar a las compañías bancarias en la planificación de acciones que representen una escala evolutiva de parámetros de políticas y acciones. Tras llenar los indicadores sugeridos por Ethos, las empresas pueden enviar sus respuestas electrónicamente al Instituto; posteriormente, los datos procesados se convierten en puntuación con calificaciones y se presentan en un informe de diagnóstico; lo que le permite que cada compañía los compare, por medio de tablas y gráficas, con el grupo de benchmarking (las diez empresas con las mejores notas) y con el promedio del grupo de empresas que respondieron al cuestionario en el mismo periodo. ${ }^{30}$

30 Instituto Ethos, Indicadores Ethos de Responsabilidad Social Empresarial 2011, São Paulo, Instituto Ethos, 2011, disponible en: http:// www1.ethos.org.br/EthosWeb/arquivo/O-A-bbe2011_ Indic_ETHOS_ESP.pdf. 
FigURA 2. TEMAS COMPONENTES DE LOS INDICADORES ETHOS

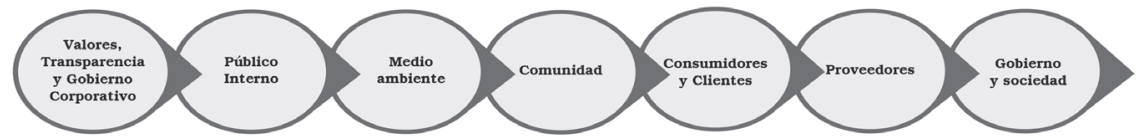

FUENTE: Elaboración propia a partir de Instituto Ethos, Indicadores Ethos de Responsabilidad Social Empresarial 2011, São Paulo, Instituto Ethos, 2011, disponible en: http:/ / www1.ethos.org. br/EthosWeb/arquivo/0-A-bbe2011_Indic_ETHOS_ESP.pdf.

El modelo Ethos consiste en siete temas componentes (véase figura 2) que comprenden un conjunto de 40 indicadores considerados para plantear cómo puede la compañía mejorar su desempeño en cada aspecto. Esa estructura permite que la banca planee el modo de fortalecer su compromiso con la RSE y, a su vez, la disposición en escala de los indicadores de profundidad provee parámetros para los pasos siguientes del proceso de autodiagnóstico que, aunado a la misión y estrategia general del corporativo le permitirá identificar aspectos de la gestión que necesitan acompañamiento detallado para evaluar los impactos de sus acciones, buscar soluciones y definir nuevas metas. ${ }^{31}$

La correlación de los Indicadores Ethos de responsabilidad social con iniciativas como el Pacto Mundial, con la Guía para la Elaboración de Memorias de Sostenibilidad del GRI, con las Directrices de la OCDE, la norma ISO 26000 y el Distintivo ESR del Cemefi seleccionado puede facilitarles a los gerentes bancarios la regulación integrada a las sinergias existentes.

\section{F. Distintivo ESR del Cemefi}

En México, uno de los principales avances en el tema de RSE es haber logrado el consenso de los principales organismos empresariales y de responsabilidad social sobre un concepto y un marco ideológico común, lo que sin duda facilita su difusión y comprensión. ${ }^{32}$

Es así como todos los organismos de la Alianza por la Responsabilidad Social Empresarial del país (AliaRSE) ${ }^{33}$ coinciden en entender la RSE como el

\section{Ibidem, p. 8.}

32 Centro Mexicano para la Filantropía, op. cit., p. 4.

33 La Alianza por la Responsabilidad Social Empresarial en México (AliaRSE), actualmente agrupa a 17 organizaciones con importantes antecedentes de trabajo en la promoción del tema en nuestro país, destacándose los seis fundadores: Cemefi, Consejo Coordinador 
Esta revista forma parte del acervo de la Biblioteca Jurídica Virtual del Instituto de Investigaciones Jurídicas de la UNAM

compromiso organizacional de desempeñarse considerando las expectativas económicas, sociales y ambientales de todos sus participantes, demostrando respeto por la gente, los valores éticos, la comunidad y el medio ambiente, contribuyendo así, a la construcción del bien común. ${ }^{34}$

Para el Cemefi, la RSE sólo se comprende reconociendo cuatro líneas o ámbitos básicos y estratégicos que se observan en la figura 3. Éstos a su vez incluyen sus respectivos subtemas, que pueden variar de un país, de un sector o de una empresa a otra pero todos son utilizables en el sector bancario. ${ }^{35}$

\section{Figura 3. Ámbitos ESTRATÉGICOS DEL DISTINTIVO \\ DE ESR DEL CEMEFI}

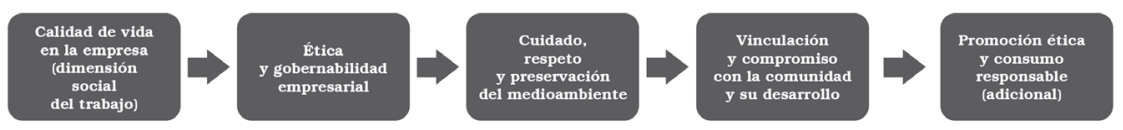

FUENTE: Elaboración propia a partir del Centro Mexicano para la Filantropía, Guía de participación para el proceso de obtención del Distintivo ESR 2016 y Manual de uso de la aplicación para responder el cuestionario diagnóstico, México, 2015, disponible en: http:/ / mww.cemefi.org/esr/images/Guia\%20 de\%20participacion\%20Distintivo\%20ESR\%202016\%20y\%20manual\%20del\%20sistem.pdf.

Con respecto al Distintivo de ESR en los bancos establecidos en México, los resultados no son muy alentadores, ya que al 2017 solamente 11 de los 51 bancos que operan en el país cuentan con el mismo: BBVA Bancomer, Santander, Banco Monex, Scotiabank, Banorte, Banco Compartamos, Banco Credit Suisse México, Banamex, Banco del Bajío y Banco Azteca que acaba de obtenerlo.

\section{ANÁLISIS DEL SECTOR BANCARIO DEL PAÍS}

La banca es posiblemente el sector económico más regulado por el Estado; su regulación, sin embargo, no siempre ha tenido entre sus ejes la promoción de la RSE como un primer objetivo. ${ }^{36}$ No obstante, gran parte del dinamismo

Empresarial (CCE), Confederación de las Uniones Sociales de Empresarios de México (Confederación USEM), la Confederación Patronal de la República Mexicana (Coparmex), la Administración por valores (Aval) posteriormente Caux Roud Table-México y el Sistema Desem (posteriormente Impulsa).

34 Ibidem, p. 8.

35 Ibidem, p. 6.

36 Rivera, Eugenio y Rodríguez, Adolfo, "Competencia y regulación en la banca de Cen- 
y de las transformaciones experimentadas por la banca centroamericana y mexicana en estos años resultan de estrategias para hacer frente a esas fuentes reguladoras externas que les exigen convertirse en corporativos más responsables socialmente.

La importancia del estudio de organizaciones bancarias radica en que son instancias de mucho peso en el desarrollo de los países (captación y canalización de recursos); por lo tanto, su comportamiento organizacional está sujeto a múltiples medidas que reglamentan su actuar; en el caso de México, estas normatividades se han tenido que redefinir a partir de períodos de crisis económicas con el fin de ajustarla a nuevos criterios mundialmente aceptados. La internacionalización de las organizaciones implica asumir o no determinadas reglas y acuerdos, de esta forma, en ocasiones, deben elegir qué reglas aceptar, las del país sede o de una localidad determinada. ${ }^{37}$

\section{Intermediarios financieros del SFM}

Actualmente, de acuerdo con la Asociación de Bancos de México (ABM), existen distintos tipos de intermediarios financieros en el SFM que captan, administran y canalizan el ahorro de las personas hacia la inversión, entre los más destacados se encuentran los bancos. Otros más son las aseguradoras, afianzadoras, arrendadoras, casas de bolsa y las administradoras de fondos de inversión. ${ }^{38}$

De todos los intermediarios financieros que operan en el país el más importante es la banca, la cual tiene como función principal canalizar el dinero que ahorran las personas para prestarlo a aquellos individuos que tienen necesidad de obtener financiamiento a través de créditos para diversos fines. A su vez, existen dos tipos de banca, la primera está compuesta por las instituciones de banca múltiple, que son todas aquellas corporaciones bancarias privadas, tanto nacionales como internacionales o globales, y el segundo tipo, es denominada banca de desarrollo, conformada por bancos públicos propiedad del gobierno federal mexicano. ${ }^{39}$

troamérica y México: un estudio comparativo", Serie Estudios y perspectivas CEPAL, México, núm. 71, 2007, p. 5.

37 Arrazate-Hernández, R. op.cit., p. 108.

38 Asociación de Bancos de México, La banca en México: bancos asociados, México, ABM, 2016, disponible en: http:// wnw.abm.org.mx/ bancos-integrantes/.

39 Banco de México, El sistema financiero, México, Banxico, 2015, disponible en: http:/ / wmw. 
A finales de 2015, estaban dadas de alta un total 46 instituciones de banca múltiple en la ABM. Sin embargo, a raíz de la RF, la SHCP autoriza el ingreso al mercado mexicano de cinco nuevos bancos, los cuales ya se han afiliado a la Asociación y están próximos a operar, el de origen nacional que ya empezó a operar en el 2016 (Banco Finterra), y cuatro extranjeros: Industrial and Commercial Bank of China (ICBC); Banco Sabadell, de España (inicia operaciones en nuestro país en enero de 2016); Shinhan Bank de Corea (autorizado en agosto del 2015 y comienza en el 2017) y Mizuho de Japón (autorizado en diciembre del 2015 y opera a partir del 2017). En contraste, el Banco Wal Mart de México deja de ser integrante la Asociación y también para 2017 inicia el mexicano: Banco Progreso de Chihuahua (autorizado en el 2014), lo que nos lleva a un total de 51 bancos privados registrados en total, tal como se muestra en la tabla 3, que señala además una clasificación de la presencia que poseen, independientemente si el país de origen es nacional o extranjero. ${ }^{40}$

TABLA 3: BANCA MÚLTIPLE REgISTRADA EN LA ABM AL 2017

\begin{tabular}{|c|c|c|}
\hline \multicolumn{3}{|c|}{ Presencia } \\
\hline Nacional & Norteamérica y / o Latinoamérica & Global \\
\hline ABC Capital & Banco Azteca & $\begin{array}{l}\text { American Express Bank } \\
\text { (México) }\end{array}$ \\
\hline Banca Afirme & Banco Base & $\begin{array}{l}\text { Banco Credit Suisse } \\
\text { (México) }\end{array}$ \\
\hline Banca Mifel & Banco Compartamos & Banco JP Morgan \\
\hline Banco Actinver & Banco Inbursa & Banco Monex \\
\hline Banco Ahorro Famsa & Banco Invex & Banco Nacional de México \\
\hline Banco Autofin México & Bancoppel & Banco Sabadell \\
\hline Banco del Bajío & Investa Bank & Banco Santander \\
\hline Banco Finterra & & Bank of America Mexico \\
\hline Banco Forjadores & & Bank of China Mexico \\
\hline $\begin{array}{l}\text { Banco Inmobiliario } \\
\text { Mexicano }\end{array}$ & & $\begin{array}{l}\text { Bank of Tokyo Mitsubishi } \\
\text { UFJ (México) }\end{array}$ \\
\hline Banco Interacciones & & Bankaool \\
\hline
\end{tabular}

banxico.org. $m x$ /divulgacion/sistema-financiero/sistema-financiero.btml\#Serviciosfinancieros.

40 Asociación de Bancos de México, Bancos afiliados, México, ABM, 2017, disponible en: bttps:// wnw.abm.org.mx/ bancos-integrantes/abm-bancos-afiliados.btm. 
Esta revista forma parte del acervo de la Biblioteca Jurídica Virtual del Instituto de Investigaciones Jurídicas de la UNAM http://www.juridicas.unam.mx/

DOl: http://dx.doi.org/10.22201/iij.24487899e.2018.26.11859

REFORMA FINANCIERA Y LA RESPONSABILIDAD SOCIAL EMPRESARIAL...

\begin{tabular}{|l|l|l|}
\hline \multicolumn{1}{|c|}{ Nacional } & Norteamérica y / o Latinoamérica & \multicolumn{1}{c|}{ Global } \\
\hline Banco Mercantil del Norte & & Barclays Bank México \\
\hline Banco Multiva & & BBVA Bancomer \\
\hline Banco PagaTodo & & Deutsche Bank México \\
\hline Banco Progreso Chihuahua & & HSBC México \\
\hline $\begin{array}{l}\text { Banco Regional de } \\
\text { Monterrey }\end{array}$ & $\begin{array}{l}\text { Industrial and Commercial } \\
\text { Bank of China }\end{array}$ \\
\hline Banco Ve por Más & Mizuho Bank \\
\hline Bancrea & & Scotiabank \\
\hline Bansí & & Shinhan Bank \\
\hline CIBanco & & UBS Bank México \\
\hline Consubanco & Volkswagen Bank \\
\hline Fundación Dondé Banco & & \\
\hline Intercam Banco & & \\
\hline
\end{tabular}

FUENTE: Elaboración propia a partir de la Asociación de Bancos de México, Bancos afiliados, 2017, disponible en: https:// wmm.abm.org.mx/ bancos-integrantes/abm-bancos-afiliados.btm.

La otra parte del sector bancario, está compuesta por la banca de desarrollo, la cual en enero de 1998 celebró un convenio de colaboración para formalizar su separación oficial de la ABM; 41 sin embargo, las seis instituciones de banca pública que la conforman a septiembre de 2015, acordaron mantener un vínculo permanente de comunicación con la Asociación para el análisis y resolución de temas afines. Para el 2016 se incorpora la Sociedad Hipotecaria Federal (SHF), al grupo de invitados especiales dando un total de siete instituciones a mediados del 2017: Banco del Ahorro Nacional y Servicios Financieros; Banco Nacional del Ejército, Fuerza Aérea y Armada; Banco Nacional de Obras y Servicios Públicos; Financiera Nacional de Desarrollo Agropecuario, Rural, Forestal y Pesquero; Nacional Financiera; Banco Nacional de Comercio Exterior y Sociedad Hipotecaria Federal.

No obstante, pese a las bondades que supone la existencia de este tipo de instituciones financieras, es preciso indicar que, en ocasiones, la teoría económica convencional no tiene en cuenta la calidad de las mismas ni los

41 Asociación de Bancos de México, La banca en México..., cit. 
problemas relacionados con la información asimétrica que proporcionan ni la competencia imperfecta, lo que puede producir niveles de financiamiento inferiores al óptimo, así como una distribución ineficiente de recursos afectando el crecimiento económico del país. ${ }^{42}$

Si bien la existencia de la banca de desarrollo puede estar plenamente justificada, la realidad es que en muchas ocasiones ha tenido un desempeño pobre enfrentando problemas que entorpecen y limitan su impacto en el desarrollo social del país; inclusive, en la mayor parte de su gestión ha otorgado poco crédito, enfocado en mantener niveles de capitalización altos y una cartera de clientes con bajos índices de morosidad como política conservadora. Por otro lado, ha logrado algunos avances con respecto a la transparencia en su acción y los subsidios que apoyan sus operaciones, así como mejoras en su gobierno corporativo y rendición de cuentas y esto es uno de los principales objetivos a atender por la reciente RF que involucra tanto la dimensión económica como social de la RSE. 43

Actualmente la banca desempeña un papel protagónico en el crecimiento y desarrollo de México: impulsa la inversión y el consumo y es un factor principal para la competitividad empresarial. Es decir, tiene la posibilidad de impactar a millones de familias, empresas de múltiples tamaños, así como emprendedores, siempre y cuando realice bien su actividad y cuide cumplir equilibradamente con todos sus indicadores, incluyendo los sociales. ${ }^{44}$

Más allá de eso, la existencia de una normativa que de alguna forma regule u obligue a las empresas a asumir actividades asociadas con la RSE es uno de los aspectos más polémicos debatidos a nivel mundial. El siglo XXI está viendo el diseño y difusión de una amplia variedad de herramientas para que las organizaciones contribuyan en mayor medida al desarrollo sostenible y la

42 Stiglitz, Joseph E. y Weiss, Andrew, "Credit Rationing in Markets with Imperfect Information”, American Economic Review, vol. 71, núm. 3, junio de 1981, pp. 393-410; Turrent, Eduardo, Historia sintética de la Banca en México, México, Banco de México, 2007, disponible en: bttp:// wmw.banxico.org. $m x$ / sistema-financiero/index. btml\#MR.

43 Turrent, Eduardo, Historia sintética de la Banca en México, Banco de México, 2007, disponible en: bttp:// www.banxico.org. $m x$ / sistema-financiero/index. btml\#MR; Levy, Noemí, "Reforma financiera y Banca de Desarrollo: créditos o ilusiones”, Economía Informa, México, núm. 382, septiembre-octubre de 2013, pp. 3-17; Vergara-Talamantes, Mario, "La Reforma Financiera y la Banca de Desarrollo: propuesta de un modelo de evaluación del desempeño de la Banca de Desarrollo Mexicana”, Revista Finanz̧as Públicas, vol. 8, núm. 19, 2015, pp. 14-19.

44 Asociación de Bancos de México, La Banca en México: compromiso social..., cit., p. 12. 
RSE, lo que al mismo tiempo puede mejorar su impacto social, la imagen corporativa y beneficiar su reputación. ${ }^{45}$

Si bien es cierto que la falta de facultad sancionadora de estas normas obstaculiza en la práctica su efectividad, es preciso aclarar que ellas cumplen una función que va mucho más allá de aplicar sanciones, Guillén, en cita a Camacho, ${ }^{46}$ asegura que lo que buscan en realidad es crear conciencia para que la práctica de una conducta responsable no sea producto de la existencia de un organismo regulador, legislaciones o normativas, sino por el contrario, que se adopten formas de comportamiento, a través de las cuales las empresas muestren ante los consumidores, los Estados y el público en general una imagen moralmente limpia y aceptable; sin embargo, hasta el momento, en el caso del sector bancario han sido necesarias múltiples regulaciones para corregir rumbos en los ámbitos de la RSE.

Con respecto a la percepción de la RSE en las empresas españolas, el Instituto Ipsos Public Affairs realiza periódicamente un estudio sobre esa situación y permite conocer la opinión de diferentes stakeholders, entre los que se encuentran primordialmente empresarios y directivos, analistas financieros y académicos. Según su informe 2010, la mayoría de los entrevistados opinan que las empresas no prestan la suficiente atención a sus responsabilidades sociales. ${ }^{47}$

En esa misma línea, De la Cuesta et al.48 Analizan el desempeño social de cuatro de las principales empresas financieras españolas detectando que la dimensión social de la RSE a menudo suele confundirse con la participación del corporativo en programas comunitarios hacia el exterior. Sin embargo, la RSE del sector bancario también debe considerar la calidad de las condiciones de trabajo, la integración de las preocupaciones sociales y el respeto de los derechos humanos.

En este sentido, García-Cossío y Pérez-Ruiz realizan un análisis en el sector bancario español que pone de manifiesto que tanto Santander como BBVA y

45 Olcese-Santonja, Aldo et al., Manual de la empresa responsable y sostenible. Conceptos y herramientas de la responsabilidad social corporativa o de la empresa, España, McGraw-Hill, 2008, p. 244.

46 Camacho-Solís, Julio Ismael, "Las normas de responsabilidad social. Su dimensión en el ámbito laboral de las empresas", Revista Latinoamericana de Derecho Social, núm. 20, enero-junio de 2015, pp. 3-29.

47 Ipsos Public Affairs, Economía, RSE y reputación corporativa de las empresas, España, IPSOS, 2010, disponible en: http:// wmm.ipsos.es/.

48 De la Cuesta-González, Marta et al., op. cit., p. 290. 
CaixaBank han mantenido sus inversiones en RSE y como consecuencia, han obtenido beneficios notables en términos de ahorro de costos, mejora de la formación de proveedores, oferta de servicios más extensa a clientes y mejor reputación corporativa. Además, los autores detectaron una falta de homogeneidad en la información de RSE aportada por las entidades bancarias, un hecho que dificulta la extracción de conclusiones y comparaciones sólidas entre los bancos estudiados. ${ }^{49}$

Del mismo modo, Duque-Orozco y Martínez-Barón se concentran en estudiar la divulgación de la RSE a través de las páginas Web empresariales y revisaron principalmente contenidos y a quién se dirigen. Aunado a lo anterior, se presenta la necesidad del establecimiento de medidas de homogeneización de la divulgación de la información sobre RSE en el sector bancario de cara a poder extraer conclusiones más acertadas en las investigaciones académicas. ${ }^{50}$

En ese sentido, Vives y Peinado-Vara, reconocen que las prácticas empresariales responsables han sufrido una evolución desde la filantropía empresarial más tradicional, pasando por la ciudadanía corporativa, hasta llegar a verdaderos esfuerzos por demostrar comportamientos responsables. ${ }^{51}$

Un estudio de Pérez-Ruiz y Rodríguez-del Bosque, pone de manifiesto que las entidades financieras aún tienen un importante camino que recorrer para alcanzar las expectativas puestas por la sociedad en sus políticas de RSE, porque hasta el momento, no parecen haber conseguido satisfacer plenamente las inquietudes sociales. ${ }^{52}$

En ese mismo marco, Aranguren-Gómez y Martínez-Cerna, ${ }^{53}$ así como Marín et al.,$^{54}$ sostienen que América Latina está en un ámbito en el que aún se

49 García-Cossío, Lourdes y Pérez-Ruiz, Andrea, "Responsabilidad social empresarial, estrategia y ventaja competitiva en el sector bancario español”, Revista de Dirección y Administración de Empresas, España, núm. 21, diciembre de 2014, pp. 64-81.

50 Duque-Orozco, Yenni Viviana y Martínez-Barón, Deissy, op. cit.

51 Vives, Antonio y Peinado-Vara, Estrella (eds.), La responsabilidad social de la empresa en América Latina. Fondo Multilateral de Inversiones, Nueva York, Washington, Banco Interamericano de Desarrollo, 2011.

52 Pérez-Ruiz, Andrea y Rodríguez del Bosque, Ignacio, "La imagen de responsabilidad Social Corporativa en un contexto de crisis económica: El caso del sector financiero en España”, Universia Business Review, España, núm. 33, 2012, pp. 14-29.

53 Aranguren-Gómez, Nagore y Martínez-Cerna, Luis, op. cit.

54 Marín-Gaviria, María del Pilar et al., "Análisis empírico de la divulgación de información 
ha indagado poco en lo que a revelación de información sobre RSE respecta y son prácticamente inexistentes los estudios en la banca. Los autores pusieron de manifiesto que la teoría de la legitimidad posiblemente sea la más utilizada a la hora de tratar de explicar la revelación de información social y medioambiental a nivel internacional.

Con respecto al análisis de contenido de los informes anuales y las páginas Web de seis bancos privados chilenos analizados por Aranguren-Gómez y Martínez-Cerna, se detectó que las instituciones revelan información muy diferente en grado y tipo sobre la RSE. Asimismo, encontraron que aquellos que otorgan mayor importancia a los rubros relacionados con la comunidad, consumidores y productos, dan menor importancia a los datos sobre medio ambiente..$^{55}$

Por otro lado, Duque-Orozco y Martínez-Barón efectuaron un estudio de las prácticas de RSE en la dimensión laboral de Bancolombia y BBVA, caracterizados por ser dos de los bancos con mayor generación de utilidades en Colombia, cada uno en su categoría: nacional e internacional respectivamente y los hallazgos fueron que las entidades bancarias estudiadas, pese a que afirman que su marco de reporte social es el GRI, no están respondiendo a dichos indicadores o presentan información sin desagregar tal como lo indica la guía. ${ }^{56}$

Es así como la forma de presentación de los datos del desempeño bancario varía en los diferentes estudios encontrados y esto atenta contra la directriz de publicación y transparencia de todas las herramientas de RSE analizadas en la presente investigación, lo que puede impedir una comparación entre los bancos.

Aunado a ello, se destaca que si bien no se puede abandonar la voluntariedad de la RSE, sí hay asuntos urgentes que solucionar en América Latina, que se concentran principalmente en tópicos sobre derechos humanos, mercados financieros estables y la falta de estandarización e interpretación de las iniciativas que es conveniente regular en el sector bancario.

Con respecto al compromiso de la banca con el desarrollo sustentable en México, se puede resaltar su principal responsabilidad: transformar los ahoros de los mexicanos en créditos para financiar las actividades productivas y

social en Chile: un estudio en empresas cotizadas", Revista Economía, Gestión y Desarrollo, Colombia, núm. 13, 2012, pp. 121-153, disponible en: http:// revistaeconomia.puj.edu.co/ html/articulos/ Numero_13/MALDONADO.pdf.

55 Aranguren-Gómez, Nagore y Martínez-Cerna, Luis, op. cit.

56 Duque-Orozco, Yenni Viviana y Martínez-Barón, Deissy, op. cit. 
de esa forma, contribuir a mejorar las condiciones de vida de las familias. Si bien, la banca se ha esforzado por ser un ciudadano corporativo responsable y solidario que realiza diversas actividades para impulsar el desarrollo económico, social y ambiental del país, aún tienen mucho por hacer para evidenciar niveles más altos de responsabilidad social, más allá de reportar resultados mediantes informes anuales. ${ }^{57}$

Hoy más que nunca, México tiene una oportunidad sin precedente de importantes reformas estructurales, de una mayor apertura a la inversión privada en sectores estratégicos, del fortalecimiento en su estructura macroeconómica y en general, de un ambiente favorable con la RSE que impulse un modelo de desarrollo económico para promover el bienestar de la población. ${ }^{58}$

Ante este panorama, algunas de las actividades que el sistema bancario ha implementado como estrategias de RSE para el desarrollo social del país son el invertir en proyectos sociales y de vinculación con las comunidades más desfavorecidas; fomentar la cultura y el arte, además de trabajo voluntario; apoyar a las comunidades afectadas por desastres naturales; incrementar la disponibilidad y variedad de herramientas para la educación financiera de la sociedad y establecer canales de diálogo con grupos de interés. ${ }^{59}$

El impacto principal de la banca en la dimensión ambiental de la RSE es que ha financiado proyectos de energías sustentables y de infraestructura con criterios socio-ambientales; además, utiliza y promueve las energías sustentables en la operación bancaria. ${ }^{60}$

Por su parte, la dimensión económica de la RSE en el desempeño de los bancos del país hace énfasis en el impulso de la bancarización e inclusión financiera y el gestionar herramientas de promoción de la satisfacción de clientes, creando productos o servicios enfocados a sus necesidades y capacidad particulares. ${ }^{61}$

En relación a la dimensión ética de la RSE, la banca establecida en México desarrolla canales de asesoría ética para colaboradores, mantiene medios de

57 Asociación de Bancos de México, Carta del presidente, México, ABM, 2015, disponible en: https:/ / www.abm.org.mx/ responsabilidad-social/2015/ carta-presidente.html.
58 Idem.
59 Idem.
60 Idem.
61 Idem. 
apelación y defensa de los derechos del cliente, capacita en normatividad ética de instituciones, anticorrupción y lavado de dinero para colaboradores y directivos e impulsa el desarrollo de buenas prácticas de gobierno corporativo. ${ }^{62}$

En específico, en el ámbito bancario nacional existen instituciones preocupadas en el actuar con RSE ante la sociedad, que publican voluntariamente en informes anuales o memorias de responsabilidad social corporativa, basados en las pautas del GRI y otras más que implementan programas de RSE, los Indicadores Ethos e inclusive son parte de la Red del Pacto Mundial en México y están trabajando bajo sus principios o aplicando la Norma ISO 26000, otras más han obtenido el Distintivo de Empresa Socialmente Responsable ante el Centro Mexicano para la Filantropía (Cemefi) de forma consecutiva, así como los bancos multinacionales que operan considerando las Directrices de la OCDE.

Exponiendo de manera breve el desempeño de logros principales sobre la Responsabilidad Social de las instituciones bancarias establecidas en el país y con respecto a sus prioridades medioambientales, sociales y de gobierno interno, se citan los siguientes ejemplos:

De los 51 bancos integrantes de la Asociación de Bancos de México $(\mathrm{ABM})$, sólo 11 instituciones financieras han obtenido el Distintivo ESR del Cemefi hasta mediados del 2017: BBVA Bancomer (17 años consecutivos), Banco Santander (trece años seguidos), Banco Monex (por trece años), Bank of America Merrill Lynch México (once años), Scotiabank (diez años), Banorte y Banco Compartamos (ambos por siete años continuos), Banco Credit Suisse México (cinco años al 2016), Banamex (cinco años), Banco del Bajío (cuatro años) y Banco Azteca acaba de obtenerlo en el 2017.

En contraste, del total de bancos en el país, solamente nueve de ellos se han adherido a la Red del Pacto Mundial de las Naciones Unidas de forma voluntaria y han alineado sus operaciones y estrategias con los diez principios sociales universalmente compartidos de la iniciativa global para actuar de manera socialmente responsable, incluyendo los objetivos de Desarrollo del Milenio: Scotiabank es el pionero y el único que es parte del Comité del Pacto Mundial en México desde 2009; Bancomer y Banorte se adhieren en el 2011; Santander y la antes conocida como Financiera Rural se suman en el 2012, Fundación Quiera de la ABM y Banamex en el 2013; Banco del Bajío (2014) 
y Bank of America Merrill Lynch México es el más reciente, incorporado en el 2016.

\section{Regulación de la banca}

El desafío de implementar políticas públicas está pendiente en muchos países de Latinoamérica y en especial en México. La transformación del negocio bancario comenzó desde la década de los setenta cuando la sofisticación del mismo produjo la transición hacia la banca múltiple, cuyas modificaciones regulatorias de 1974 y de 1978 representaron en su momento el reconocimiento a una tendencia irreversible para la regulación de la banca. ${ }^{63}$

Este concepto ha ido avanzando poco a poco, ya que la banca funcionó en México con sus propios usos y costumbres hasta el 20 de abril de 1884 cuando se decretó un nuevo Código de Comercio que incluyó por primera vez preceptos aplicables a los bancos. En 1889 se promulgó un nuevo Código que desechó los privilegios del Banco Nacional de México y requería de nuevo la autorización, caso por caso, para los bancos de parte de la Secretaría de Hacienda y del Congreso de la Unión. Ello generó un caos hasta que en 1897 se emitió la Ley General de Instituciones de Crédito con la cual se crearon bases generales y uniformes para el establecimiento de bancos y se les sujetó a la vigilancia permanente de la Secretaría de Hacienda inclusive al control del crédito a los propios directivos y consejeros de los mismos. ${ }^{64}$

Se dio una simbiosis entre los capitales de la banca, la industria y el comercio, que facilitó sus relaciones y desarrollo. Sin embargo, los vacíos legales, y la crisis de liquidez por la situación mundial de 1907, motivó que en 1908 se promulgaran reformas a la Ley General de Instituciones de Crédito de 1897 que, entre otros objetivos, redujeron la multiplicidad de instituciones emisoras, limitaron y regularon más estrictamente el préstamo a directores bancarios y exigieron más claridad en los balances. ${ }^{65}$

El desarrollo experimentado en otros mercados financieros a mediados de los ochenta y el creciente flujo de capitales a escala internacional, fueron tam-

63 Asociación de Bancos de México, La banca en México. Breves sintesis de grandes Transformaciones (1982-1996), México, ABM, disponible en: https:/ / mmw.abm.org.mx/ descargas/1982_1996.pdf.

64 Asociación de Bancos de México, La Banca en México Breves Sintesis de sus Orígenes (18301910), México, ABM, disponible en: https:// wmw.abm.org.mx/descargas/1982_1996.pdf.

65 Idem. 
bién incentivos que aceleraron la innovación en el mercado constituyendo el siguiente eje de la RF. Así, entre 1983 y 1991 se diversificaron las opciones de ahorro para el inversionista y los canales de financiamiento. Es este período maduraron productos como la cuenta maestra, los depósitos preestablecidos y los pagarés. ${ }^{66}$

Un tercer eje de la RF se estableció a finales de 1989 con el cambio en las regulaciones de mercado, que abarcan, entre otras, la expedición de reformas a las Leyes para Instituciones de Crédito y para el Mercado de Valores, y un paquete de regulaciones para grupos financieros. Con este paquete se crearon las bases para la operación de dichos grupos y de sus sociedades controladoras, figura que posteriormente se convirtió en el eje para la creación de las nuevas entidades bancarias. ${ }^{67}$

Con respecto a las posteriores búsquedas legales para normar el desempeño del sector bancario, surgieron un conjunto de reformas legales que dieron paso a la iniciativa de reforma constitucional para restablecer el régimen mixto en la prestación del servicio de banca y crédito, la cual se aprobó en mayo de 1990, donde fue creado el Comité de Desincorporación Bancaria, que intervino como cuerpo colegiado para diseñar y ejecutar la privatización de la banca en coordinación con la Comisión Intersecretarial de Gasto Financiamiento, quien fungió como órgano principal en la toma de decisiones para crear un SFM más competitivo y eficiente, obtener una participación diversificada en el capital de los bancos y promover la descentralización de las operaciones para favorecer el desarrollo regional. Además, se buscó la transparencia en la valuación de las entidades, utilizando para ello criterios generales uniformes y de amplia aceptación. ${ }^{68}$

La superación de las antiguas regulaciones y el favorable desempeño en las finanzas públicas permitieron entonces diversificar la asignación de crédito, por lo que entre 1988 y 1993 las proporciones de recursos dirigidas a la industria, la vivienda y el consumo crecieron, en contraste con la contracción del crédito asignado al gobierno. ${ }^{69}$

En contrapartida, el bienio 1993-1994 manifestó de inmediato debilidades que marcaron de origen el nacimiento del nuevo SFM. Una de ellas fue el de

\footnotetext{
66 Asociación de Bancos de México, La banca en México breves sintesis de grandes..., cit.

67 Idem.

68 Idem.

69 Idem.
} 
la deficiente o irregular operación con que algunas administraciones comenzaron a manejarse. La responsabilidad social en el manejo de los recursos quedó seriamente comprometida y de hecho, poco tiempo después, desembocó en la intervención de las instituciones. ${ }^{70}$

Debido a las reformas se profundizó en la evaluación del desempeño de la banca en América Latina, pero lamentablemente no aumentó el desarrollo financiero ni el comportamiento responsable de los bancos hacia sus stakeholders internos ni externos. Entonces, no es suficiente liberar y regular los mercados financieros para hacerlos competitivos ni responsables, sino que se precisen políticas explícitas de financiación del desarrollo que reconozcan la importancia de los bancos como instrumentos que respondan a políticas de complementación financiera para apoyar a sectores de alta rentabilidad económica y social. ${ }^{71}$

Parcialmente, como resultado de los efectos de las reformas financieras, el grado de profundización de la dimensión económica de la RSE se incrementó en un gran número de países entre 1990 y 1999. De 2004 a 2012, el conjunto de modificaciones regulatorias dirigidas al sector bancario tuvieron como principales objetivos establecer una regulación semejante a la de los mercados internacionales para facilitar el flujo de capitales financieros y la adopción de nuevos instrumentos de inversión, lo que profundizó el dinamismo del sector y su vinculación con los mercados externos al adoptarse nuevas prácticas y una regulación más convergente. ${ }^{72}$

Sin embargo, estas reglamentaciones aún corresponden a iniciativas generales. En esta discusión seguimos el planteamiento de la crisis financiera que afectó los periodos de 2007 a 2010, atribuida tanto a irresponsabilidades empresariales como a la negligencia de los organismos reguladores, lo que agudizó la sensibilidad general hacia el tema de la RSE con la sociedad. ${ }^{73}$ Como respuesta a esos agravios que surgieron y ante las nuevas legislaciones a las que tiene que enfrentarse el sector bancario, la RSE ha evolucionado, para

70 Idem.

71 Calderón-Alcas, Romy, "La banca de desarrollo en América Latina y el Caribe", Serie Financiamiento del Desarrollo CEPAL, Santiago de Chile, núm. 157, 2005.

72 Calderón-Alcas, Romy, op. cit., Turrent, Eduardo, op. cit.

73 Vives y Peinado-Vara, op. cit. 
hacer cada vez más partícipe y responsable a la empresa en la definición del tipo de sociedad a la que aspira.

Es así como Rodríguez-Nava y Dorantes-Hernández señalan que, después de la crisis financiera internacional, surge la necesidad de adoptar mecanismos prudenciales que permitan a las autoridades financieras identificar y evaluar fenómenos de carácter económico-financiero capaces de generar interrupciones del SFM y en caso de detectar algún riesgo de esta naturaleza, prever un mecanismo de respuesta coordinada. ${ }^{74}$

Bajo este contexto, el Banco de México (Banxico) establece el 29 de julio de 2010, un acuerdo del Ejecutivo Federal, para crear el Consejo de Estabilidad del SFM (CESF). El CESF está presidido por la SHCP e integrado por los titulares del Banxico, de la CNBV, de la Comisión Nacional de Seguros y Fianzas (CNSF), de la Comisión Nacional del Sistema de Ahorro para el Retiro (Consar) y del Instituto para la Protección al Ahorro Bancario (IPAB). La presidencia del Consejo recae en la SHCP y su secretaría en el Banxico. ${ }^{75}$

En adelante, se observa la tendencia a favorecer los flujos financieros de forma regulada y la concordancia del sector bancario con las prácticas de los mercados internacionales para una evaluación continua de la acumulación de fuentes de riesgo sistémico que puedan afectar la estabilidad del SFM.

Posteriormente, la ABM establece un marco regulatorio para facilitar el acceso a la legislación y regulación aplicable a los intermediarios financieros, en especial a los bancos, compuesto por una serie de leyes y tratados internacionales resumidos en la tabla 4, aparte de las autoridades financieras mexicanas que fungen como autoridades financieras reguladoras del comportamiento responsable de la banca: SHCP, Banxico, CNBV, Consar, CNSF, IPAB y la Comisión Nacional para la Protección y Defensa de los Usuarios de Servicios Financieros (Condusef). ${ }^{76}$

74 Rodríguez-Nava, A. y Dorantes-Hernández, P. M., "La reciente reforma financiera en México: transformaciones y perspectivas”, Economía, México, vol. 13, núm. 37, 2016, p. 6.

75 Banco de México, El sistema financiero, 2015, disponible en: http:// mmw.banxico.org.mx/ divulgacion/sistema-financiero/sistema-financiero.html\#Serviciosfinancieros.

76 Asociación de Bancos de México, La banca en México: marco regulatorio, México, ABM, 2016, disponible en: http:// wmw.abm.org.mx/la-banca-en-mexico/abm-marco-regulatorio.htm. 
TABLA 4. REGULACIÓN Y LEGISLACIÓN DE LA BANCA

\begin{tabular}{|c|c|}
\hline Legislación & Tratados internacionales \\
\hline $\begin{array}{l}\text { Constitución Política de los Estados } \\
\text { Unidos Mexicanos }\end{array}$ & $\begin{array}{l}\text { Tratado de Libre Comercio de América } \\
\text { del Norte. }\end{array}$ \\
\hline Código Civil Federal & $\begin{array}{l}\text { Convención de la Organización de Coopera- } \\
\text { ción y Desarrollo Económicos. }\end{array}$ \\
\hline Código de Comercio & $\begin{array}{l}\text { Acuerdo de cooperación entre el gobierno de } \\
\text { México y el gobierno de Italia en materia de } \\
\text { lucha contra el crimen organizado. }\end{array}$ \\
\hline $\begin{array}{l}\text { Código Federal de Procedimientos } \\
\text { Civiles }\end{array}$ & $\begin{array}{l}\text { Acuerdo de cooperación en materia de asis- } \\
\text { tencia jurídica entre el gobierno de México y el } \\
\text { gobierno de Colombia. }\end{array}$ \\
\hline Código Fiscal de la Federación & $\begin{array}{l}\text { Acuerdo de cooperación mutua entre México } \\
\text { y España, Francia, Panamá, Guatemala para el } \\
\text { intercambio de información respecto de ope- } \\
\text { raciones financieras realizadas para prevenir y } \\
\text { combatir operaciones de procedencia ilícita o } \\
\text { de lavado de dinero. }\end{array}$ \\
\hline Ley de Instituciones de Crédito & $\begin{array}{l}\text { Acuerdo de cooperación mutua entre el go- } \\
\text { bierno de México y el gobierno de los Esta- } \\
\text { dos Unidos de América para el intercambio } \\
\text { de información respecto de transacciones } \\
\text { en moneda realizadas a través de institucio- } \\
\text { nes financieras para combatir actividades } \\
\text { ilícitas. }\end{array}$ \\
\hline $\begin{array}{l}\text { Ley de la Comisión Nacional Bancaria } \\
\text { y de Valores }\end{array}$ & $\begin{array}{l}\text { Acuerdo de cooperación económica y finan- } \\
\text { ciera entre México y España. }\end{array}$ \\
\hline Ley del Banco de México & $\begin{array}{l}\text { Acuerdo de sede entre México y el Banco de } \\
\text { Pagos Internacionales en Relación con el esta- } \\
\text { blecimiento y estatuto de una oficina de repre- } \\
\text { sentación del Banco de Pagos Internacionales } \\
\text { en México. }\end{array}$ \\
\hline Ley de Protección al Ahorro Bancario & $\begin{array}{l}\text { Acuerdo entre el gobierno de México y Aus- } \\
\text { tralia, Polonia, Estados Unidos para evitar la } \\
\text { doble imposición e impedir la evasión fiscal } \\
\text { en materia de impuestos sobre la renta. }\end{array}$ \\
\hline $\begin{array}{l}\text { Ley de Protección y Defensa al Usuario } \\
\text { de Servicios Financieros }\end{array}$ & $\begin{array}{l}\text { Acuerdo entre el gobierno de México y el go- } \\
\text { bierno de Canadá sobre la aplicación de sus } \\
\text { leyes de competencia. }\end{array}$ \\
\hline
\end{tabular}




\begin{tabular}{|c|c|}
\hline Legislación & Tratados internacionales \\
\hline Ley del Mercado de Valores & $\begin{array}{l}\text { Acuerdo entre el gobierno de México y la Or- } \\
\text { ganización de Cooperación y Desarrollo Eco- } \\
\text { nómicos sobre Privilegios e Inmunidades en la } \\
\text { Organización en México. }\end{array}$ \\
\hline $\begin{array}{l}\text { Ley General de Organizaciones y Acti- } \\
\text { vidades Auxiliares del Crédito }\end{array}$ & $\begin{array}{l}\text { Acuerdo para el Fomento de la Inversión en- } \\
\text { tre el Gobierno de los México y el Gobierno } \\
\text { de los Estados Unidos de América. }\end{array}$ \\
\hline Ley General de Sociedades Mercantiles & $\begin{array}{l}\text { Acuerdo entre el gobierno de México y Argen- } \\
\text { tina, Italia, Alemania, Austria, Unión Econó- } \\
\text { mica Belgo-Luxemburguesa, Corea, Cuba, Di- } \\
\text { namarca, Finlandia, Francia, Grecia, Portugal, } \\
\text { Suecia, Suiza, Uruguay, España para la promo- } \\
\text { ción y protección recíproca de las inversiones. }\end{array}$ \\
\hline $\begin{array}{l}\text { Ley General de Títulos y Operaciones } \\
\text { de Crédito }\end{array}$ & $\begin{array}{l}\text { Acuerdo entre el gobierno de México y el } \\
\text { gobierno de Colombia para el intercambio de } \\
\text { información no judicializada. }\end{array}$ \\
\hline $\begin{array}{l}\text { Ley para la Transparencia y Ordena- } \\
\text { miento de los Servicios Financieros }\end{array}$ & $\begin{array}{l}\text { Acuerdo entre el gobierno de México y el } \\
\text { gobierno de Polonia sobre cooperación para } \\
\text { combatir la delincuencia organizada y otros } \\
\text { tipos de delitos. }\end{array}$ \\
\hline $\begin{array}{l}\text { Ley para regular las Agrupaciones } \\
\text { Financieras }\end{array}$ & $\begin{array}{l}\text { Acuerdo interino sobre comercio y cuestiones } \\
\text { relacionadas con el comercio entre México y la } \\
\text { Comunidad Europea. }\end{array}$ \\
\hline $\begin{array}{l}\text { Ley para regular las Sociedades de In- } \\
\text { formación Crediticia }\end{array}$ & $\begin{array}{l}\text { Código de Factoraje Internacional de Dere- } \\
\text { chos Aduaneros. }\end{array}$ \\
\hline Ley de Ahorro y Crédito Popular & $\begin{array}{l}\text { Convención para Combatir el Cohecho de } \\
\text { Servidores Públicos Extranjeros en Transac- } \\
\text { ciones Comerciales Internacionales. }\end{array}$ \\
\hline Ley de Concursos Mercantiles & $\begin{array}{l}\text { Convención Interamericana sobre Conflictos } \\
\text { de Leyes en Materia de Sociedades Mercanti- } \\
\text { les. }\end{array}$ \\
\hline Ley de Inversión Extranjera & $\begin{array}{l}\text { Convención de las Naciones Unidas contra la } \\
\text { Delincuencia Organizada Transnacional. }\end{array}$ \\
\hline $\begin{array}{l}\text { Ley de Transparencia y de Fomento a la } \\
\text { Competencia en el Crédito Garantizado }\end{array}$ & $\begin{array}{l}\text { Convención Interamericana sobre Derecho } \\
\text { Aplicable a los Contratos Internacionales. }\end{array}$ \\
\hline $\begin{array}{l}\text { Ley Federal de Competencia } \\
\text { Económica }\end{array}$ & $\begin{array}{l}\text { Convención de Viena sobre el Derecho de los } \\
\text { Tratados. }\end{array}$ \\
\hline $\begin{array}{l}\text { Ley Federal de Procedimiento Adminis- } \\
\text { trativo }\end{array}$ & $\begin{array}{l}\text { Convención Interamericana sobre Arbitraje } \\
\text { Comercial Internacional. }\end{array}$ \\
\hline
\end{tabular}




\begin{tabular}{|c|c|}
\hline Legislación & Tratados internacionales \\
\hline $\begin{array}{l}\text { Ley para el Desarrollo de la Compe- } \\
\text { titividad de la Micro, Pequeña y Me- } \\
\text { diana Empresa }\end{array}$ & $\begin{array}{l}\text { Convención Interamericana sobre Conflictos } \\
\text { de Leyes en Materia de Letras de Cambio, Pa- } \\
\text { garés y Facturas. }\end{array}$ \\
\hline $\begin{array}{l}\text { Ley Federal de Extinción de Domi- } \\
\text { nio, Reglamentaria del Artículo } 22 \text { de } \\
\text { la Constitución Política de los Estados } \\
\text { Unidos Mexicanos }\end{array}$ & $\begin{array}{l}\text { Convención de las Naciones Unidas sobre } \\
\text { Letras de Cambio Internacionales y Pagarés } \\
\text { Internacionales. }\end{array}$ \\
\hline \multirow{10}{*}{$\begin{array}{l}\text { Ley Federal de Protección de Datos } \\
\text { Personales en Posesión de los Particu- } \\
\text { lares }\end{array}$} & $\begin{array}{l}\text { Convención sobre la Obtención de Pruebas } \\
\text { en el Extranjero en Materia Civil o Comercial. }\end{array}$ \\
\hline & $\begin{array}{l}\text { Convención Interamericana sobre Régimen } \\
\text { Legal de Poderes para ser Utilizados en el } \\
\text { Extranjero. }\end{array}$ \\
\hline & $\begin{array}{l}\text { Convención por la que se Suprime el Requisi- } \\
\text { to de Legalización de los Documentos Públi- } \\
\text { cos Extranjeros. }\end{array}$ \\
\hline & $\begin{array}{l}\text { Convenio Internacional para la Represión de } \\
\text { la Financiación del Terrorismo. }\end{array}$ \\
\hline & $\begin{array}{l}\text { Convenio-Marco entre los Estados Unidos } \\
\text { Mexicanos y la Comunidad Europea, Relativo } \\
\text { a la Ejecución de la Ayuda Financiera y Técni- } \\
\text { ca y de la Cooperación Económica en México, } \\
\text { en Virtud del Reglamento. }\end{array}$ \\
\hline & $\begin{array}{l}\text { Convenio entre el Gobierno de los Estados } \\
\text { Unidos Mexicanos y el Gobierno del Reino } \\
\text { Unido de Gran Bretaña e Irlanda del Norte } \\
\text { para Evitar la Doble Imposición e Impedir la } \\
\text { Evasión Fiscal en materia de Impuestos sobre } \\
\text { la Renta y Ganancias de Capital. }\end{array}$ \\
\hline & $\begin{array}{l}\text { Convenio sobre la Notificación o Traslado en } \\
\text { el Extranjero de Documentos Judiciales o Ex- } \\
\text { trajudiciales en Materia Civil o Comercial. }\end{array}$ \\
\hline & $\begin{array}{l}\text { Protocolo relativo a las inmunidades del Banco } \\
\text { de Pagos Internacionales. }\end{array}$ \\
\hline & $\begin{array}{l}\text { Tratado de Cooperación entre los Estados } \\
\text { Unidos Mexicanos y los Estados Unidos de } \\
\text { América sobre Asistencia Jurídica Mutua. }\end{array}$ \\
\hline & $\begin{array}{l}\text { Tratado de Extradición y Asistencia Mutua en } \\
\text { Materia Penal entre los Estados Unidos Mexi- } \\
\text { canos y el Reino de España. }\end{array}$ \\
\hline
\end{tabular}


Esta revista forma parte del acervo de la Biblioteca Jurídica Virtual del Instituto de Investigaciones Jurídicas de la UNAM

\begin{tabular}{|l|l|}
\hline Legislación & \multicolumn{1}{|c|}{ Tratados internacionales } \\
\hline & Tratado de Extradición entre los Estados \\
& Unidos Mexicanos y los Estados Unidos de \\
& América, firmado en la Ciudad de México. \\
\hline
\end{tabular}

FUENTE: Elaboración propia a partir de la Asociación de Bancos de México, La banca en México: marco regulatorio, 2016b, disponible en: http://wmw.abm.org.mx/la-banca-en-mexico/abmmarco-regulatorio.htm.

Aún existen numerosos asuntos por resolver para construir un entorno que brinde a la sociedad los satisfactores que necesita, pero es necesario contar con el apoyo de las instituciones bancarias que disfrutan día con día de mayor influencia y poder. Es por ello que su aporte debe ser cada vez más significativo para la cimentación de una economía con crecimiento sostenible, que permita un mayor compromiso con la sociedad traducido en una relación recíproca que encuentre a la RSE como una forma de retribución urgente en el sector bancario. ${ }^{77}$

Se ha afirmado que el sector bancario es uno de los sectores con mayor influencia en el sistema económico, por lo que la toma de conciencia del impacto que el buen funcionamiento del SFM tiene sobre el bienestar de la población, lleva a la necesidad de asumir, en toda su amplitud, a la RSE como eje fundamental en gobierno corporativo de la banca.

Por su parte, Morfín-Maciel, ${ }^{78}$ señala que el Programa Nacional de Financiamiento del Desarrollo 2008-2012 ha identificado ocho objetivos específicos para promover la eficiencia y profundidad en la RSE de los servicios financieros y en estos casos, desde el punto de vista de la eficiencia económica, se justificaría, en principio, la intervención del gobierno:

a) Fomentar una mayor captación e intermediación del ahorro, así como la canalización eficiente de recursos a los proyectos de inversión más rentables.

b) Aumentar la penetración del SFM, promoviendo que una mayor proporción de la población cuente con acceso a este tipo de servicios.

77 Cajiga-Calderón, Juan Felipe, El concepto de responsabilidad social empresarial, México, Centro Mexicano para la Filantropía, Cemefi S.A., disponible en: http://wmw.cemefi.org/esr/images/ stories/pdf/esr/concepto_esr.pdf.

78 Morfín-Maciel, Antonio, "Banca de desarrollo y el apoyo al acceso (México)", Serie Financiamiento del Desarrollo CEPAL, Santiago de Chile, núm. 208, 2005. 
c) Incrementar la competencia entre intermediarios financieros, mediante la entrada continua de nuevos participantes y la promoción de mayor transparencia en los productos y servicios ofrecidos.

d) Fortalecer el papel de los mercados de deuda y capitales en el financiamiento al sector privado, alentando el desarrollo de nuevos instrumentos de ahorro, inversión y manejo de riesgos.

e) Garantizar la seguridad, solidez y estabilidad del SFM, a través del fortalecimiento de la regulación financiera y aplicación de reformas cuando sea necesario.

f) Desarrollar la cultura financiera y protección al consumidor, propiciando que los individuos se conciban como sujetos capaces de ahorrar, obtener financiamiento para sus proyectos productivos, cumplir obligaciones crediticias y protegerse de los riesgos financieros que enfrentan.

g) Consolidar el Sistema Nacional de Pensiones.

h) Fortalecer y dar impulso a la banca de desarrollo, logrando su consolidación como instrumento de política para desarrollar mercados financieros, y ampliar el acceso a los mismos para los sectores de mayor influencia económica y social, impactando en este rubro la dimensión social de la RSE.

En cuanto al conjunto de reformas promulgadas en enero de 2014, se reúnen modificaciones a la legislación financiera tendientes a establecer las condiciones para las operaciones del crédito, para la integración efectiva del sector a través de la subcontratación de servicios financieros y mayores controles en la exposición a riesgos, así como para la adopción de estrategias que promuevan la inclusión financiera, un aspecto que es necesario atender de acuerdo a las recomendaciones del GRI, Indicadores Ethos y los principios del Pacto Mundial para la RSE. ${ }^{79}$

Aunado a lo anterior, se revisa la actual RF, para verificar si es posible el cambio de un comportamiento voluntario de los bancos hacia uno más supervisado que impacte favorablemente su responsabilidad social.

La reforma empieza por buen camino impactando de forma general tanto la dimensión económica como social de la RSE, al facilitar que los usuarios del sector bancario puedan cambiar libremente sus cuentas de banco o crédi-

\footnotetext{
79 Rodríguez-Nava, Abigail y Dorantes-Hernández, Patricia Margarita, op. cit., p. 90.
} 
to a la institución que les ofrezca mejores tasas de interés o beneficios. Además, se observa la intención que la RF tiene para facilitar el financiamiento de un proyecto productivo e instalar una nueva empresa, lo cual es congruente con el ámbito estratégico del Cemefi de vinculación y compromiso con el desarrollo de la comunidad.

\section{La Reforma Financiera}

A más de tres años y medio de la promulgación de la RF vigente en México, podemos hacer un recuento de los principales avances logrados a la fecha, la cual está sustentada en los objetivos fundamentales de: incrementar la competencia en el sector financiero, fomentar el crédito a través de la banca de desarrollo, ampliar el crédito mediante instituciones financieras privadas, mantener un SFM sólido y hacer más eficaces a las instituciones financieras y sus respectivas autoridades. ${ }^{80}$

Se ha avanzado en su implementación principalmente en rubros que impactan los principios de RSE de rendición de cuentas y respeto a los intereses de stakeholders, tales como el fomento de una mayor competencia entre bancos y la defensa de los usuarios, pero la mayor parte de las empresas sigue sin recurrir al crédito de la banca, además, quedan cosas por hacer con respecto a la inclusión financiera, especialmente para los sectores vulnerables de las zonas más marginadas del país. En ese sentido, la mayoría de veces la RSE está lejos de la conciencia corporativa de los bancos y, por lo general, se queda en agendas para aplicar en el futuro. ${ }^{81}$

Con la intención de impactar al primer objetivo de incrementar la competencia en el sector financiero en México, y profundizar sobre el impacto económico y social de la RSE en la banca, el Instituto Mexicano para la Competitividad realizó un estudio titulado La Reforma Financiera y los riesgos del crédito, encontrando que tan sólo cinco instituciones financieras concentran el $73 \%$ del otorgamiento de créditos, Bancomer BBVA y Banamex tienen una participación del 34\% del mercado y el resto Banorte, Santander y HSBC, lo

\footnotetext{
80 Publicado en el Diario Oficial de la Federación, 2014.

81 Chambers, C. y Day, R., "The Banking Sector and CSR: An Unholy Alliance?”, Review Financial Regulation International, vol. 12, núm. 9, 2009, p. 13.
} 
que limita el acceso, la cobertura y la expansión de su oferta. ${ }^{82}$ En ese sentido, cabe resaltar que el financiamiento ha sido particularmente escaso para las Micro, Pequeñas y Medianas Empresas (MiPyMEs), las cuales generan cerca del $74 \%$ del empleo en el país y la mayoría de ellas han podido financiarse únicamente a través de canales informales.

Así mismo, la Comisión Federal de Competencia Económica (Cofece) llevó a cabo una investigación sobre las condiciones de competencia del SFM para cumplir con una de las primeras recomendaciones de la Reforma y establecer las bases de un desarrollo incluyente, efectuando un diagnóstico sobre la situación de la competencia en el sector financiero con el propósito de formular recomendaciones a las autoridades financieras para evitar prácticas anticompetitivas y buscar así la reducción de tasas de interés e impactar la materia fundamental de RSE de prácticas justas de operación. ${ }^{83}$

De igual manera, una serie de medidas asociadas a la RF para fomentar la competencia dentro del SFM y que se relacionan con el principios de RSE sobre el respeto a los intereses de stakeholders son: prohibir que los bancos vendan productos condicionados a la compra de otros (ventas atadas); expandir la oferta crediticia a mejores precios; facilitar la movilidad de garantías y de operaciones; aumentar el número de corresponsales de ahorro y crédito popular; la creación del buró de entidades financieras, y con respecto a los principios de RSE sobre respeto al principio de legalidad y rendición de cuentas, se relaciona el hecho que los bancos deben atender las sanciones administrativas que les sean impuestas para el fortalecimiento de la Condusef. ${ }^{84}$

En cuanto al objetivo de la RF que busca fomentar el crédito a través de la banca de desarrollo se presenta la necesidad de cambiar la política conservadora en el otorgamiento de crédito que en los últimos años se ha mantenido para evitar mantener niveles de capitalización altos y una cartera de clientes

82 Instituto Mexicano para la Competitividad, La Reforma Financiera y los riesgos del crédito, México, Imco, 2013, p.10, disponible en: http:/ / imco.org.mx/wp-content/uploads/2013/09/LaReformaFinancierayLosRiesgosdelCredito.pdf.

83 Comisión Federal de Competencia Económica, Plan Estratégico 2014-2017, México, Cofece, 2015, disponible en: https:// wnw.cofece.mx/cofece/index.php.

84 Comisión Nacional para la Protección y Defensa de los Usuarios de Servicios Financieros, La Reforma Financiera es para ti, México, Condusef, 2015, http:/ / www.condusef.gob.mx / Revistal index.php/usuario-inteligente/condusef-responde/476-reforma-financiera-resultados. 
con bajos índices de morosidad. Por ello se realizaron modificaciones al marco legal de esos bancos con el fin de que otorguen más crédito a las áreas y actividades prioritarias del país, actuando en conjunto con la banca comercial y otros intermediarios financieros.

Es decir, con la RF se busca fortalecer el mandato de la banca de desarrollo, estableciendo como prioridad brindar acceso al crédito, otorgar asistencia técnica y capacitación para contribuir con la actividad productiva del país, proveer la inclusión financiera de la población en general y particularmente, la de mujeres, niños y jóvenes, así como la promoción del ahorro e inversión en comunidades indígenas. Lo anterior con especial énfasis en las áreas prioritarias para el desarrollo nacional, como son: infraestructura, apoyo a las MiPyMEs y pequeños productores del campo, innovación, creación de patentes, y en general todas aquellos sectores no atendidos por la banca privada, fomentando la sustentabilidad ambiental, la perspectiva de género, la inclusión financiera y aumentando las funciones de banca social..$^{85}$

La RF busca aumentar el crédito a través del sector bancario tanto público como privado para dejar atrás la escasa penetración que ha tenido el crédito en México en los últimos años y las principales acciones para impulsarlo son: simplificar los regímenes para el otorgamiento y ejecución de garantías crediticias, lograr una reducción de los riesgos a efecto de brindar mayor seguridad jurídica a los otorgantes de crédito, y la evaluación anual del desempeño del sector bancario sobre el nivel de crédito otorgado a las fuerzas productivas del país y su contribución a la economía nacional.

Adicionalmente, la RF busca hacer más eficaz la operación del sector bancario y el actuar de las autoridades financieras sobre éste para el mejor funcionamiento de SFM. Con esa intención, moderniza la legislación e impacta el tema de valores, transparencia y gobierno corporativo de los Indicadores Ethos y el ámbito estratégico de ética y gobernabilidad del Cemefi a través de las siguientes medidas: flexibilización del régimen corporativo de los fondos de inversión, fortalecimiento del régimen del mercado de valores, sube a rango de ley tanto el Consejo Nacional de Inclusión Financiera como el Comité de Educación Financiera y fortalece las sanciones para todos los intermediarios financieros en conjunto con sus usuarios.

85 Levy, Noemí, op. cit; Vergara-Talamantes, Mario, op. cit. 
Con respecto a las modificaciones penales señaladas en el Diario Oficial de la Federación (2014) se atienden los principios de RSE de rendición de cuentas, transparencia y legalidad, ayudando al sector bancario a recaudar las garantías de préstamos incobrables, e incluso, le permite retener bienes como garantías físicas o solicitar que los deudores no podrán ausentarse del lugar donde se realiza el juicio en su contra ni cambiar de domicilio sin avisar para que los bancos reduzcan el riesgo al otorgar créditos.

Otro punto importante de la RF señaladas en el Diario Oficial de la Federación que atiende principalmente la dimensión social de la RSE en el principio de derechos humanos e intereses de los consumidores, es el facilitar la portabilidad bancaria, que permite la movilidad de operaciones entre instituciones, por ejemplo, en caso de tener contratado un crédito con determinado banco y llega otro a ofrecer una tasa de interés más benévola o mejores condiciones para pagarlo, se pueda emigrar con facilidad.

Así mismo, la Condusef ${ }^{86}$ señala que se publicaron en el Diario Oficial de la Federación en enero de 2014 las Disposiciones de Carácter Aplicables a las Entidades Financieras en Materia de Despachos de Cobranza, que se relacionan con los principios de RSE sobre derechos de los stakeholders, humanos y transparencia, donde se les exige a las instituciones entre otras cosas: identificarse plenamente, dirigirse al deudor respetuosamente, contactarle entre las 07:00 y las 22:00 horas, usar números de teléfono identificables, no utilizar nombres o denominaciones que se asemejen a las de las instituciones públicas, no amenazar, ofender o intimidar, abstenerse de realizar gestiones de cobro a terceros, a excepción de los deudores solidarios o avales, no establecer listas negras, cartelones o anuncios que hagan del conocimiento del público la negativa de pago de los deudores, no realizar gestiones de cobranza, negociación o reestructuración con menores de edad o con adultos mayores, a excepción de que en el último caso se trate del deudor.

En la misma línea del fomento responsable de la transparencia operativa, a octubre de 2014, se presentaron ante la Condusef un total de 7,623 controversias por gestiones de cobranza indebidas, de las cuales 5,372 corresponden a gestiones de cobranza sin ser el cliente deudor, 1,538 por maltrato u ofensas

86 Comisión Nacional para la Protección y Defensa de los Usuarios de Servicios Financieros, op.cit., p. 20. 
y 539 por un crédito que ya se encuentra liquidado. ${ }^{87}$ En cambio, en materia de hacer más eficaces a las autoridades la RF sigue avanzando, por ejemplo, las sanciones impuestas por la Condusef a diversas instituciones financieras aumentaron $32 \%$ en el 2015, al sumar 5,070 contra las 3,841 registradas en el 2014, cuyas causas primordiales son el omitir la presentación de informes trimestrales de consultas y reclamaciones, no exhibir documentos o elementos solicitados en los procedimientos conciliatorios, no proporcionar o validar información para el registro de prestadores de servicios financieros, emitir tarjetas de crédito sin solicitud de los usuarios; y no registrar comisiones en el sistema respectivo; lo que muestra un comportamiento poco favorecedor para la RSE de los bancos involucrados.

En contraste, como parte de los objetivos y recomendaciones de la RF se realiza la primera evaluación de desempeño de los bancos que operaban al 2015 en el país y los resultados se dieron a conocer públicamente a finales de julio de 2016 por la SHCP. Dicha evaluación consta de la suma de dos partes: por un lado el índice de la misma es el factor cuantitativo que se calcula con base en indicadores del Buró de Entidades Financieras, CNBV y otros reportes regulatorios que presentan la banca (incluye indicadores sobre grado de intermediación tales como cartera, morosidad y captación; de infraestructura en sucursales, productos y servicios; así como calidad de servicios) según la Condusef. 88

La segunda revisión corresponde a un cuestionario estratégico que respondieron los bancos, donde describen todo tipo de acciones y programas incluyendo los de RSE para la orientación y cumplimiento de su objeto social, la promoción del desarrollo de las fuerzas productivas del país, fomento al ahorro, descentralización del sistema, y canalización de recursos a una cobertura regional.

Aunque no entra en muchos detalles en sus resultados públicos, la SHCP enlista los 37 bancos con más de cinco años de operación al 2015; también anexa a petición propia al Banco Bancrea (autorizado apenas en el 2013) y se limita a mencionar que cada uno de éstos obtuvo un resultado satisfactorio en su evaluación (como se muestra en la tabla 5). ${ }^{89}$

87 Ibidem, p. 21.

88 Idem.

89 Secretaría de Hacienda y Crédito Público, Comunicado de prensa 099, México, SHCP, 2016, disponible en: https:// www.gob.mx/shcp/prensa/comunicado-de-prensa-099-2016. 
TABLA 5: INSTITUCIONES DE BANCA MÚLTIPLE

(MÁS DE CINCO AÑOS DE OPERACIÓN AL 2015)

\begin{tabular}{|c|c|c|}
\hline & Nombre de la institución de banca múltiple & Resultado final \\
\hline 1 & ABC Capital, S.A., Institución de Banca Múltiple & Satisfactorio \\
\hline 2 & $\begin{array}{l}\text { American Express Bank (México), S.A., Institución de } \\
\text { Banca Múltiple }\end{array}$ & Satisfactorio \\
\hline 3 & $\begin{array}{l}\text { Banca Afirme, S.A., Institución de Banca Múltiple, Afirme } \\
\text { Grupo Financiero }\end{array}$ & Satisfactorio \\
\hline 4 & $\begin{array}{l}\text { Banca Mifel, S.A., Institución de Banca Múltiple, Grupo } \\
\text { Financiero Mifel }\end{array}$ & Satisfactorio \\
\hline 5 & $\begin{array}{l}\text { Banco Actinver, S.A., Institución de Banca Múltiple, } \\
\text { Grupo Financiero Actinver }\end{array}$ & Satisfactorio \\
\hline 6 & Banco Ahorro Famsa, S.A., Institución de Banca Múltiple & Satisfactorio \\
\hline 7 & Banco Autofin México, S.A., Institución de Banca Múltiple & Satisfactorio \\
\hline 8 & Banco Azteca, S.A., Institución de Banca Múltiple & Satisfactorio \\
\hline 9 & Banco Bancrea, S.A., Institución de Banca Múltiple & Satisfactorio \\
\hline 10 & Banco Compartamos, S.A., Institución de Banca Múltiple & Satisfactorio \\
\hline 11 & $\begin{array}{l}\text { Banco Credit Suisse (México), S.A., Institución de Banca } \\
\text { Múltiple, Grupo Financiero Credit Suisse (México) }\end{array}$ & Satisfactorio \\
\hline 12 & Banco del Bajío, S.A., Institución de Banca Múltiple & Satisfactorio \\
\hline 13 & $\begin{array}{l}\text { Banco Inbursa, S.A., Institución de Banca Múltiple, } \\
\text { Grupo Financiero Inbursa }\end{array}$ & Satisfactorio \\
\hline 14 & $\begin{array}{l}\text { Banco Interacciones, S.A., Institución de Banca Múltiple, } \\
\text { Grupo Financiero Interacciones }\end{array}$ & Satisfactorio \\
\hline 16 & $\begin{array}{l}\text { Banco Invex, S.A., Institución de Banca Múltiple, Invex } \\
\text { Grupo Financiero }\end{array}$ & Satisfactorio \\
\hline 16 & $\begin{array}{l}\text { Banco J.P. Morgan, S.A., Institución de Banca Múltiple, } \\
\text { J.P. Morgan Grupo Financiero }\end{array}$ & Satisfactorio \\
\hline 17 & $\begin{array}{l}\text { Banco Mercantil del Norte, S.A., Institución de Banca } \\
\text { Múltiple, Grupo Financiero Banorte }\end{array}$ & Satisfactorio \\
\hline 18 & $\begin{array}{l}\text { Banco Monex, S.A., Institución de Banca Múltiple, Monex } \\
\text { Grupo Financiero }\end{array}$ & Satisfactorio \\
\hline 19 & $\begin{array}{l}\text { Banco Multiva, S.A. Institución de Banca Múltiple, Grupo } \\
\text { Financiero Multiva }\end{array}$ & Satisfactorio \\
\hline 20 & $\begin{array}{l}\text { Banco Nacional de México, S.A. Integrante Del Grupo } \\
\text { Financiero Banamex }\end{array}$ & Satisfactorio \\
\hline
\end{tabular}




\begin{tabular}{|c|c|c|}
\hline 21 & $\begin{array}{l}\text { Banco Regional de Monterrey, S.A., Institución de Banca } \\
\text { Múltiple, Banregio Grupo Financiero }\end{array}$ & Satisfactorio \\
\hline 22 & $\begin{array}{l}\text { Banco Santander (México), S.A., Institución de Banca } \\
\text { Múltiple, Grupo Financiero Santander México }\end{array}$ & Satisfactorio \\
\hline 23 & $\begin{array}{l}\text { Banco Ve por Más, S.A., Institución de Banca Múltiple, } \\
\text { Grupo Financiero Ve por Más }\end{array}$ & Satisfactorio \\
\hline 24 & Bancoppel, S.A. Institución de Banca Múltiple & Satisfactorio \\
\hline 25 & $\begin{array}{l}\text { Bank of America México, S.A., Institución de Banca } \\
\text { Múltiple }\end{array}$ & Satisfactorio \\
\hline 26 & $\begin{array}{l}\text { Bank of Tokyo-Mitsubishi UFJ (México), S.A., Institución } \\
\text { de Banca Múltiple Filial }\end{array}$ & Satisfactorio \\
\hline 27 & Bansí, S.A., Institución de Banca Múltiple & Satisfactorio \\
\hline 28 & $\begin{array}{l}\text { Barclays Bank México, S.A., Institución de Banca Múltiple, } \\
\text { Grupo Financiero Barclays México }\end{array}$ & Satisfactorio \\
\hline 29 & $\begin{array}{l}\text { BBVA Bancomer, S.A., Institución de Banca Múltiple, } \\
\text { Grupo Financiero BBVA Bancomer }\end{array}$ & Satisfactorio \\
\hline 30 & CIBanco, S. A., Institución de Banca Múltiple & Satisfactorio \\
\hline 31 & Consubanco, S.A., Institución de Banca Múltiple & Satisfactorio \\
\hline 32 & Deutsche Bank México, S.A., Institución de Banca Múltiple & Satisfactorio \\
\hline 33 & $\begin{array}{l}\text { HSBC México, S.A., Institución de Banca Múltiple, } \\
\text { Grupo Financiero HSBC }\end{array}$ & Satisfactorio \\
\hline 34 & $\begin{array}{l}\text { Intercam Banco, S.A., Institución de Banca Múltiple, } \\
\text { Intercam Grupo Financiero }\end{array}$ & Satisfactorio \\
\hline 35 & Investa Bank, S.A., Institución de Banca Múltiple & Satisfactorio \\
\hline 36 & $\begin{array}{l}\text { Scotiabank Inverlat, S.A., Institución de Banca Múltiple, } \\
\text { Grupo Financiero Scotiabank Inverlat }\end{array}$ & Satisfactorio \\
\hline 37 & $\begin{array}{l}\text { UBS Bank México, S.A., Institución de Banca Múltiple, UBS } \\
\text { Grupo Financiero }\end{array}$ & Satisfactorio \\
\hline 38 & Volkswagen Bank, S.A., Institución de Banca Múltiple & Satisfactorio \\
\hline
\end{tabular}

FUENTE: Elaboración propia a partir de Secretaría de Hacienda y Crédito Público, Comunicado deprensa 099, 2016, disponible en: https:// www.gob.mx/shcp/prensa/ comunicado-de-prensa-099-2016.

También se evalúa a otras seis instituciones con menos de cinco años de operación al 2015, aunque éstas son evaluadas solamente para efectos indicativos y de seguimiento, cinco de ellas obtuvieron un resultado satisfactorio, excepto Fundación Dondé Banco que llevaba operando como banco, apenas tres años al momento de esta evaluación (tabla 6). 
TABLA 6: INSTITUCIONES DE BANCA MÚLTIPLE (MENOS DE CINCO AÑOS AL 2015)

\begin{tabular}{|l|l|c|}
\hline & \multicolumn{1}{|c|}{ Nombre de la institución de banca múltiple } & Resultado final \\
\hline 1 & $\begin{array}{l}\text { Banco Base, S.A., Institución de Banca Múltiple, Grupo } \\
\text { Financiero Base }\end{array}$ & Satisfactorio \\
\hline 2 & Banco Forjadores, S.A., Institución de Banca Múltiple & Satisfactorio \\
\hline 3 & $\begin{array}{l}\text { Banco Inmobiliario Mexicano, S.A., Institución de Banca } \\
\text { Múltiple }\end{array}$ & Satisfactorio \\
\hline 4 & Banco PagaTodo, S.A., Institución de Banca Múltiple & Satisfactorio \\
\hline 5 & Bankaool, S.A., Institución de Banca Múltiple & Satisfactorio \\
\hline 6 & Fundación Dondé Banco, S.A., Institución de Banca Múltiple & No satisfactorio \\
\hline
\end{tabular}

FUENTE: Elaboración propia a partir de Secretaría de Hacienda y Crédito Público, Comunicado deprensa 099, 2016, disponible en: https:// wmw.gob.mx/shcp/prensa/ comunicado-de-prensa-099-2016.

Sin embargo, como el contenido de la información no es detallada para todos los stakeholders del sector bancario ni hay evidencia clara de los resultados obtenidos, solamente se informa sobre el resultado final, lo que resulta insuficiente para demostrar un desempeño satisfactorio con respecto a la RSE de sus operaciones.

Posteriormente, el 31 de julio 2017, la SHCP presenta los resultados de la segunda evaluación de desempeño de la banca y derivado de la RF que estará realizando anualmente, con el fin de verificar que los bancos contribuyan efectivamente en las materias de prácticas justas de operación, asuntos de consumidores y participación activa en el desarrollo de la comunidad.

Con fundamento en el quinto y vigésimo segundo de los "Lineamientos para la evaluación de desempeño de las instituciones de banca múltiple”, publicados por la SHCP el 31 de diciembre de 2014 en el Diario Oficial de la Federación, emitidos con fundamento en los artículos 275 al 281 del título octavo de la Ley de Instituciones de Crédito denominado "De la Evaluación de Desempeño de las Instituciones de Banca Múltiple”, adicionado mediante el Decreto por el que se Reforman, Adicionan y Derogan Diversas Disposiciones en Materia Financiera y se Expide la Ley para Regular las Agrupaciones Financieras, publicado en el Diario Oficial de la Federación el 10 de enero de 2014; así como a lo establecido en la "Resolución por la que se modifican los Lineamientos para la evaluación de desempeño de las instituciones de banca 
múltiple", publicada en el Diario Oficial de la Federación el 11 de enero de 2017 la SHCP, se presenta la resolución final de la evaluación de desempeño 2016 de las instituciones que conforman al sector de banca múltiple.

Los resultados finales de la segunda evaluación de desempeño de la banca que realizó la SHCP, se presentan en orden alfabético e incluyen a las instituciones con más de cinco años de operación al 2016; así como a Banco Inmobiliario Mexicano, que solicitó de manera voluntaria ser objeto de la evaluación, de conformidad con lo establecido en el artículo tercero de los Lineamientos citados.

En la tabla 7 se percibe que tres bancos tuvieron un resultado insatisfactorio: el alemán Deutsche Bank, el mexicano InvestaBank y el suizo UBS, los cuales presentan a la fecha situaciones notables, dado que el primero está en proceso de venta de sus activos precisamente a InvestaBank, mismo que a su vez ha tenido problemas de capital, además de que fue protagonista de un escándalo a finales del 2016. En el caso de UBS, se sabe que está en un proceso de migración de su negocio en México.

TABLA 7: INSTITUCIONES DE BANCA MÚLTIPLE

(MÁS DE CINCO AÑOS DE OPERACIÓN AL 2016)

\begin{tabular}{|l|l|c|}
\hline & \multicolumn{1}{|c|}{ Nombre de la institución de banca múltiple } & Resultado final \\
\hline 1 & ABC Capital, S.A., Institución de Banca Múltiple & Satisfactorio \\
\hline 2 & $\begin{array}{l}\text { American Express Bank (México), S.A., Institución de Banca } \\
\text { Múltiple }\end{array}$ & Satisfactorio \\
\hline 3 & $\begin{array}{l}\text { Banca Afirme, S.A., Institución de Banca Múltiple, Afirme } \\
\text { Grupo Financiero }\end{array}$ & Satisfactorio \\
\hline 4 & $\begin{array}{l}\text { Banca Mifel, S.A., Institución de Banca Múltiple, Grupo Fi- } \\
\text { nanciero Mifel }\end{array}$ & Satisfactorio \\
\hline 5 & $\begin{array}{l}\text { Banco Actinver, S.A., Institución de Banca Múltiple, Grupo } \\
\text { Financiero Actinver }\end{array}$ & Satisfactorio \\
\hline 6 & Banco Ahorro Famsa, S.A., Institución de Banca Múltiple & Satisfactorio \\
\hline 7 & Banco Autofin México, S.A., Institución de Banca Múltiple & Satisfactorio \\
\hline 8 & Banco Azteca, S.A., Institución de Banca Múltiple & Satisfactorio \\
\hline 9 & $\begin{array}{l}\text { Banco Base, S.A., Institución de Banca Múltiple, Grupo Fi- } \\
\text { nanciero Base }\end{array}$ & Satisfactorio \\
\hline
\end{tabular}




\begin{tabular}{|c|c|c|}
\hline & Nombre de la institución de banca múltiple & Resultado final \\
\hline 10 & Banco Compartamos, S.A., Institución de Banca Múltiple & Satisfactorio \\
\hline 11 & $\begin{array}{l}\text { Banco Credit Suisse (México), S.A., Institución de Banca } \\
\text { Múltiple, Grupo Financiero Credit Suisse (México) }\end{array}$ & Satisfactorio \\
\hline 12 & Banco del Bajío, S.A., Institución de Banca Múltiple & Satisfactorio \\
\hline 13 & $\begin{array}{l}\text { Banco Inbursa, S.A., Institución de Banca Múltiple, Grupo } \\
\text { Financiero Inbursa }\end{array}$ & Satisfactorio \\
\hline 14 & $\begin{array}{l}\text { Banco Inmobiliario Mexicano, S.A., Institución de Banca } \\
\text { Múltiple }\end{array}$ & Satisfactorio \\
\hline 15 & $\begin{array}{l}\text { Banco Interacciones, S.A., Institución de Banca Múltiple, } \\
\text { Grupo Financiero Interacciones }\end{array}$ & Satisfactorio \\
\hline 16 & $\begin{array}{l}\text { Banco Invex, S.A., Institución de Banca Múltiple, Invex } \\
\text { Grupo Financiero }\end{array}$ & Satisfactorio \\
\hline 17 & $\begin{array}{l}\text { Banco J.P. Morgan, S.A., Institución de Banca Múltiple, J.P. } \\
\text { Morgan Grupo Financiero }\end{array}$ & Satisfactorio \\
\hline 18 & $\begin{array}{l}\text { Banco Mercantil del Norte, S.A., Institución de Banca Múlti- } \\
\text { ple, Grupo Financiero Banorte }\end{array}$ & Satisfactorio \\
\hline 19 & $\begin{array}{l}\text { Banco Monex, S.A., Institución de Banca Múltiple, Monex } \\
\text { Grupo Financiero }\end{array}$ & Satisfactorio \\
\hline 20 & $\begin{array}{l}\text { Banco Multiva, S.A. Institución de Banca Múltiple, Grupo } \\
\text { Financiero Multiva }\end{array}$ & Satisfactorio \\
\hline 21 & $\begin{array}{l}\text { Banco Nacional de México, S.A. Integrante Del Grupo Fi- } \\
\text { nanciero Banamex }\end{array}$ & Satisfactorio \\
\hline 22 & $\begin{array}{l}\text { Banco Regional de Monterrey, S.A., Institución de Banca } \\
\text { Múltiple, Banregio Grupo Financiero }\end{array}$ & Satisfactorio \\
\hline 23 & $\begin{array}{l}\text { Banco Santander (México), S.A., Institución de Banca Múlti- } \\
\text { ple, Grupo Financiero Santander México }\end{array}$ & Satisfactorio \\
\hline 24 & $\begin{array}{l}\text { Banco Ve por Más, S.A., Institución de Banca Múltiple, Gru- } \\
\text { po Financiero Ve por Más }\end{array}$ & Satisfactorio \\
\hline 25 & Bancoppel, S.A. Institución de Banca Múltiple & Satisfactorio \\
\hline 26 & $\begin{array}{l}\text { Bank of America México, S.A., Institución de Banca Múl- } \\
\text { tiple }\end{array}$ & Satisfactorio \\
\hline 27 & $\begin{array}{l}\text { Bank of Tokyo-Mitsubishi UFJ (México), S.A., Institución } \\
\text { de Banca Múltiple Filial }\end{array}$ & Satisfactorio \\
\hline 28 & Bansí, S.A., Institución de Banca Múltiple & Satisfactorio \\
\hline 29 & $\begin{array}{l}\text { Barclays Bank México, S.A., Institución de Banca Múltiple, } \\
\text { Grupo Financiero Barclays México }\end{array}$ & Satisfactorio \\
\hline 30 & $\begin{array}{l}\text { BBVA Bancomer, S.A., Institución de Banca Múltiple, Gru- } \\
\text { po Financiero BBVA Bancomer }\end{array}$ & Satisfactorio \\
\hline
\end{tabular}


Esta revista forma parte del acervo de la Biblioteca Jurídica Virtual del Instituto de Investigaciones Jurídicas de la UNAM http://www.juridicas.unam.mx/

\begin{tabular}{|c|c|c|}
\hline & Nombre de la institución de banca múltiple & Resultado final \\
\hline 31 & CIBanco, S. A., Institución de Banca Múltiple & Satisfactorio \\
\hline 32 & Consubanco, S.A., Institución de Banca Múltiple & Satisfactorio \\
\hline 33 & Deutsche Bank México, S.A., Institución de Banca Múltiple & No Satisfactorio \\
\hline 34 & $\begin{array}{l}\text { HSBC México, S.A., Institución de Banca Múltiple, Grupo } \\
\text { Financiero HSBC }\end{array}$ & Satisfactorio \\
\hline 35 & $\begin{array}{l}\text { Intercam Banco, S.A., Institución de Banca Múltiple, } \\
\text { Intercam Grupo Financiero }\end{array}$ & Satisfactorio \\
\hline 36 & Investa Bank, S.A., Institución de Banca Múltiple & No Satisfactorio \\
\hline 37 & $\begin{array}{l}\text { Scotiabank Inverlat, S.A., Institución de Banca Múltiple, } \\
\text { Grupo Financiero Scotiabank Inverlat }\end{array}$ & Satisfactorio \\
\hline 38 & $\begin{array}{l}\text { UBS Bank México, S.A., Institución de Banca Múltiple, UBS } \\
\text { Grupo Financiero }\end{array}$ & No Satisfactorio \\
\hline 39 & Volkswagen Bank, S.A., Institución de Banca Múltiple & Satisfactorio \\
\hline
\end{tabular}

FUENTE: Elaboración de las autoras a partir del Diario Oficial de la Federación de 11 de enero de 2017.

A partir de esta evaluación, se encuentra que en el 2016 aumentó el número de bancos que mostró un desempeño insatisfactorio, de acuerdo con los parámetros de la SHCP, pues en la primera evaluación en el 2015, sólo Dondé Banco obtuvo ese resultado, aunque como era una entidad con menos de cinco años de operación como tal, no tenía la obligación de cumplir con ese requisito. En la reciente evaluación ya no se ubicó en esa categoría.

De acuerdo con los lineamientos, se considera para la evaluación un índice que incluye temas como grado de intermediación financiera de la entidad (cartera, morosidad y captación), de infraestructura (sucursales y productos), la calidad de los servicios, evaluada principalmente por la Condusef. Asimismo, se evalúan las acciones y programas de las instituciones bancarias tomando en cuenta aspectos como la orientación y el cumplimiento en el desarrollo de su objeto social, el apoyo y promoción del desarrollo de las fuerzas productivas del país, el fomento del ahorro, la descentralización del sistema y la canalización de recursos a una cobertura regional, entre otros aspectos.

De esta manera, de los 39 bancos con más de cinco años de operación evaluados en el 2016, 36 obtuvieron resultados satisfactorios y los tres ya referidos fueron los que registraron resultados no satisfactorios, de acuerdo con la SHCP. Aunque tampoco estaba obligado, dado que en el 2016 tenía 
menos de cinco años de operación, Banco Inmobiliario Mexicano solicitó, de manera voluntaria, ser objeto de la evaluación y tuvo un resultado positivo.

Otros con menos de cinco años de operación al 2016 - Bancrea, Finterra, Forjadores, Pagatodo, Sabadell, Bankaool, Dondé Banco y el Industrial and Commercial Bank of China México- fueron evaluados sólo para efectos indicativos y de seguimiento; es decir, tampoco estaban obligados y también tuvieron resultados satisfactorios (tabla 8).

TABLA 8: INSTITUCIONES DE BANCA MÚLTIPLE

(MENOS DE CINCO AÑOS AL 2016)

\begin{tabular}{|l|l|l|}
\hline & \multicolumn{1}{|c|}{ Nombre de la institución de banca múltiple } & Resultado final \\
\hline 1 & Banco Bancrea, S.A., Institución de Banca Múltiple & Satisfactorio \\
\hline 2 & Banco Finterra, S.A., Institución de Banca Múltiple & Satisfactorio \\
\hline 3 & Banco Forjadores, S.A., Institución de Banca Múltiple & Satisfactorio \\
\hline 4 & Banco PagaTodo, S.A., Institución de Banca Múltiple & Satisfactorio \\
\hline 5 & Banco Sabadell, S.A., Institución de Banca Múltiple & Satisfactorio \\
\hline 6 & Bankaool, S.A., Institución de Banca Múltiple & Satisfactorio \\
\hline 7 & $\begin{array}{l}\text { Fundación Dondé Banco, S.A., Institución de Banca } \\
\text { Múltiple }\end{array}$ & Satisfactorio \\
\hline 8 & $\begin{array}{l}\text { Industrial And Commercial Bank of China México, } \\
\text { S.A., Institución de Banca Múltiple }\end{array}$ & Satisfactorio \\
\hline
\end{tabular}

FUENTE: Elaboración de las autoras a partir del Diario Oficial de la Federación, 11 de enero de 2017.

A decir de la propia SHCP, los bancos que obtuvieron un resultado no satisfactorio en la evaluación de desempeño, deberán presentar un plan en los siguientes meses para subsanar sus deficiencias en posteriores ejercicios. $\mathrm{Al}$ cierre de junio pasado operaban en el país 48 bancos. Recientemente se ha anunciado el acuerdo para que Ve por Más compre Bankaool, algo que deberá avalar la autoridad.

Además, en la evaluación de desempeño de la banca del 2016, no se incluyó al japonés Mizuho Bank, dado que inició operaciones como tal en el país apenas en marzo del presente año.

Teniendo más opciones bancarias, se espera la reducción del costo del crédito; promover la competencia efectiva en el sector bancario; incentivar más la entrada de nuevos participantes, fomentar el ahorro en todos los sectores y regiones del país, y realizar acciones enfocadas en los seis ejes rectores de 
la reciente Política Nacional de Inclusión Financiera (PNIF), cuyos ejes complementarios comprenden: fomento de conocimientos para el uso eficiente y responsable del SFM; uso de innovaciones tecnológicas para la inclusión financiera, desarrollo de infraestructura en zonas desatendidas; mayor acceso y uso de servicios formales para la población excluida, mayor confianza a través de mecanismos de protección al consumidor y mediciones para evaluar los esfuerzos en materia de RSE.

\section{REFLEXIÓN FINAL}

La banca es una actividad que a nivel mundial se torna cada vez más dinámica. En el caso de México, las nuevas medidas tomadas a partir de la reciente $\mathrm{RF}$, transitan por transformaciones en cuanto al marco regulatorio para facilitar la supervisión y el diseño de nuevos criterios para la medición de los riesgos de crédito y de mercado, con el fin de mantener niveles de capitalización acordes a los riesgos tomados por el intermediario.

Después de analizar el contenido de la RF en términos de la Responsabilidad Social del sector bancario establecido en México, se detectó una aportación principalmente en la dimensión económica y en menor medida a la dimensión social. En ese sentido, la actual Reforma no es tan representativa en términos de regular al sector bancario para que implemente la RSE de manera integral, pero sí atiende algunas necesidades prioritarias para la sociedad mexicana que pueden vincularse a elementos puntuales de las principales iniciativas y herramientas voluntarias de RSE mencionadas en este estudio analítico.

Esto tampoco resulta suficiente para aumentar los niveles de RSE de los corporativos bancarios analizados, por lo que se comprueba la hipótesis planteada de que la citada RF no contribuye en la mejora del desempeño bancario, en términos de RSE.

Por el momento, los bancos del país han demostrado una capacidad de adaptación a los objetivos de la RF; sin embargo, diversos factores ajenos a ella atentan contra su capacidad de regular a la banca para que sea posible que el sector bancario demuestre un desempeño organizacional más responsable desde la perspectiva social. Es decir, se deberán ejecutar de manera complementaria herramientas más puntuales y eficientes de esa naturaleza que sean 
permanentes tanto en la banca de desarrollo como en la banca múltiple para el financiamiento al desarrollo del país. ${ }^{90}$

De acuerdo con Clavellina ${ }^{91}$ y Vergara-Talamantes, ${ }^{92}$ esto puede requerir la alineación de los programas de gobierno, tanto el Programa Nacional de Desarrollo (PND) como el Programa Nacional de Financiamiento al Desarrollo (PNFD), con los objetivos de la banca de desarrollo y de hacer partícipe a la banca múltiple en el otorgamiento de crédito a los distintos sectores productivos del país. Además, se necesita que el sector bancario amplíe sus nichos de mercado y pueda atender a un mayor número de personas en zonas alejadas de los centros urbanos, por la latente necesidad social que todavía no se abarca dentro de la dimensión social de la RSE.

Con la RF se complementa un marco jurídico que promueve la competencia de las opciones de crédito para los mexicanos. Asimismo, se fortalece la regulación para su desempeño responsable en algunos huecos percibidos de las dimensiones económica y social de la RSE. Sin embargo, bajo las nuevas leyes aprobadas se requiere que el gobierno federal trabaje intensamente en la implementación eficaz de cada una de las modificaciones legislativas realizadas y continúe revisándolas, pues no debe olvidarse que se encuentra dentro del marco de una política pública, que busca atender un problema específico para un sector determinado, por lo que si su aplicación es exitosa, una vez terminados los plazos correspondientes, se debe actualizar o inclusive reconsiderar su vigencia ajustando sus legislaciones internas para dar cumplimiento a los acuerdos y objetivos prioritarios.

Además del impacto económico que se destaca principalmente, y en segundo término el aspecto social que implica la RF, es necesario profundizar en materia laboral de la RSE para incentivar la creación de empleos principalmente en jóvenes, mujeres y adultos mayores. De igual manera, se debe regular la práctica de la subcontratación u outsourcing, para evitar que se abuse de esta figura en las contrataciones de personal bancario. Asimismo, brindar una mayor protección a los trabajadores ante los casos de acoso y hostigamiento, así como en situaciones de embarazo, lactancia, paternidad

\footnotetext{
90 Rivera, Eugenio y Rodríguez, Adolfo, op. cit., p.13.

91 Clavellina-Miller, José Luis, "Crédito bancario y crecimiento económico en México", Economía Informa, núm. 378, enero-febrero de 2013, p. 34.

92 Vergara-Talamantes, Mario, op. cit.
} 
y discapacidad para elevar su impacto social como se publicó en el Diario Oficial de la Federación en enero de 2014.

Otros puntos a destacar como elementos positivos de la reforma son la adopción de las prácticas de control de riesgos en el sector bancario, referentes a la materia fundamental de prácticas justas de operación y asuntos controles de capital y liquidez; la creación de nuevos órganos reguladores y supervisores que reduzcan las posibilidades de incurrir en riesgos sistémicos; y lo que parece más atinado es la evaluación del desempeño de la banca que estarán realizando anualmente las autoridades financieras mexicanas; sin embargo, debería de profundizarse al respecto. ${ }^{93}$ En ese sentido, la participación del Estado deberá asumir un rol más activo que sólo ser garante de la legalidad y exigir la publicación de información financiera detallada y totalmente estandarizada entre los bancos de México.

Adicionalmente, la RF favorece la materia fundamental de RSE de participación activa, desarrollo de la comunidad y el principio de transparencia, mediante la información compilada en el buró de entidades financieras, ${ }^{94}$ que a raíz de la misma, se le facultó para difundir las características de los productos financieros: comisiones, reclamaciones presentadas por los usuarios, sanciones administrativas impuestas, cláusulas abusivas de contratos, así como toda aquella información adicional que se desee consultar para poder tomar una mejor decisión al contratar un servicio o producto financiero.

De este modo, Camacho ${ }^{95}$ sostiene de manera conjunta con la sociedad civil y el Estado, la banca asumiría un rol fundamental en el proceso destinado al respeto de los derechos laborales y humanos, para lograr una sociedad más justa, equilibrada y sustentable. Idealmente, daría origen a una cadena virtuosa que genere una dinámica simétrica de acción orientada por los principios y materias fundamentales de la RSE, con el sinnúmero de stakeholders que intervienen en su proceso social, económico y comercial, transformando positivamente a la comunidad mexicana.

93 Rodríguez-Nava, Abigail y Dorantes-Hernández, Patricia Margarita, op. cit., p. 105.

94 Administrado y regulado por la SHCP, el Banxico y la CNBV, la Condusef y la Procuraduría Federal del Consumidor (Profeco).

95 Camacho-Solís, Julio Ismael, "Las normas de responsabilidad social. Su dimensión en el ámbito laboral de las empresas”, Revista Latinoamericana de Derecho Social, núm. 20, enero-junio de 2015 , p. 3. 
Si bien hay avances en las acciones de la RF que favorecen a los usuarios de los servicios financieros, en términos de oferta de crédito, inclusión financiera, mejores mecanismos para evitar prácticas abusivas en la contratación de servicios y amplitud de información sobre la banca y sus actividades, todavía hay margen para favorecer en materia de RSE sobre asuntos de consumidores, por ejemplo, en lo referente a las tasas, cuotas y comisiones que limitan el acceso al crédito; en la escasa promoción e incentivos para el crédito con finalidades productivas y, principalmente, en la falta de controles de los activos en las instituciones financieras que ante la perspectiva de obtener mayores ganancias, pierden de vista los objetivos sociales. ${ }^{96}$

Es un hecho que las nuevas perspectivas para la banca en México están aún por definirse, pero también lo es que las transformaciones no cesarán e incluso el Estado deberá ejercer una rectoría más amplia del SFM, a fin de que éste oriente fundamentalmente sus actividades a apoyar y promover el desarrollo de las fuerzas productivas del país y el crecimiento de la economía nacional con apego a sanas prácticas de RSE y usos bancarios.

En resumen, la RF por sí sola no puede cambiar el enfoque de la estrategia corporativa bancaria de aumentar la obtención de ganancias, ampliar el cobro de servicios y la cartera de clientes; pese a que gracias a ésta, las tasas de interés activas han bajado, continúan siendo muy altas para la mayor parte de la población.

El reto está en lograr la evolución de la filantropía hacia la sostenibilidad, e impulsar la participación de más bancos en grupos de trabajo como el Pacto Mundial, la aplicación de los indicadores de desempeño del GRI, la norma ISO 26000, los indicadores Ethos y en general de cualquier otra iniciativa que les sirva de soporte para contribuir en su desempeño socialmente responsable.

Con la certeza de que tarde o temprano la participación activa de los bancos establecidos en México, en una economía abierta y globalizada, con el apoyo de la RF, de políticas públicas, así como de herramientas nacionales e internacionales de RSE, permitirán una evaluación y comunicación transparente del desempeño del sector bancario y que haya no solamente más crédito, sino más barato.

Por último, se debe resaltar que este panorama exploratorio abre la posibilidad a un amplio campo de investigación sobre la RSE en el sector bancario,

\footnotetext{
96 Rodríguez-Nava, Abigail y Dorantes-Hernández, Patricia Margarita, op. cit., p. 104.
} 
ya que como se evidencia, no ha sido un tema suficientemente examinado en nuestro país, el cual se convierte en un espacio de estudio, por el papel que juega la banca frente a las demandas sociales de países en desarrollo como el nuestro. El nivel de utilidades versus inversión social, los resultados e impactos generados por las prácticas de RSE llevadas a cabo por los bancos, y la escasa homogeneidad en la publicación de dicha información, así como las implicaciones de las Reformas Financieras, son espacios de investigación potencial que requieren ser explorados.

\section{FUENTES DE INVESTIGACIÓN}

ArAngurEn-GÓmEZ, Nagore y MARTíneZ-CERnA, Luis, "Divulgación de información sobre responsabilidad social por los bancos chilenos: Una aproximación desde la teoría de la legitimidad", Economía Global e Gestão, vol. 15, núm. 2, 2010.

Arcas-Lario, Narciso y Briones-Peñalver, Antonio Juan, "Responsabilidad social empresarial de las organizaciones de la economía social. Valoración de la misma en las empresas de la región de Murcia", Revista de Economía Pública, Socialy Cooperativa, España, vol. 65, núm. 1, 2009.

ARrAZATE-HERNÁNDEZ, R., "Responsabilidad social en el sector bancario: un estudio de caso", Revista de Administración y Organizaciones: Compromiso y responsabilidad socialy ambiental de las organizaciones, vol. 2, núm. 24, 2010.

Asociación de Bancos de México, La Banca en México Breves Sintesis de sus Orígenes (1830-1910), México, ABM, disponible en: https:/ / www.abm.org. $m x /$ descargas/1982_1996.pdf.

Asociación DE BAncos DE MÉxiCO, La Banca en México breves sintesis de grandes transformaciones (1982 - 1996), México, ABM, disponible en: https:/ / www.abm.org.mx/descargas/1982_1996.pdf.

Asociación de BAncos DE MÉxiCO, La Banca en México: compromiso social $y$ desarrollo sustentable. Informe de Responsabilidad Social y Sustentabilidad de la Banca, México, ABM, 2013, disponible en: https://mmm.abm.org.mx/ responsabilidad-social/2013/index.html. 
Asociación de Bancos De MÉxico, Carta del presidente, México, ABM, 2015, disponible en: https:// wmw.abm.org.mx/responsabilidad-social/2015/ carta-presidente. html.

Asociación de Bancos de MéXiCO, La Banca en México: bancos asociados, México, ABM, 2016, disponible en: bttp:// mmw.abm.org.mx/bancos-integrantes/.

ASOCIACIÓN DE BANCOS DE MÉXICO, La banca en México: marco regulatorio, México, ABM, 2016, disponible en: http://mww.abm.org.mx/la-banca-en-mexico/ abm-marco-regulatorio.htm.

Asociación de Bancos de México, Bancos afiliados, México, ABM, 2017, disponible en: https://www.abm.org.mx/bancos-integrantes/abm-bancos-afiliados.htm.

BANCO DE MÉxico, El sistema financiero, México, Banxico, 2015, disponible en: http:// mmw.banxico.org. $m x$ / divulgacion/sistema-financiero/sistema-financiero. btml\#Serviciosfinancieros.

CAJIGA-CALDERÓn, Juan Felipe, El concepto de responsabilidad social empresarial, Cemefi, México, disponible en: http://wnw.cemefi.org/esr/images/stories/pdf/ esr/concepto_esr.pdf.

CALDERÓN-AlCAS, Romy, "La banca de desarrollo en América Latina y el Caribe", Serie financiamiento del desarrollo CEPAL, Santiago de Chile, núm. 157, 2005.

CAMACHO-SOLÍs, Julio Ismael, "Las normas de responsabilidad social. Su dimensión en el ámbito laboral de las empresas”, Revista Latinoamericana de Derecho Social, núm. 20, enero-junio de 2015.

CENTRO MEXICANO PARA LA FILANTROPÍA, Guia de participación para el proceso de obtención del Distintivo ESR 2016 y Manual de uso de la aplicación para responder el cuestionario diagnóstico, México, Cemefi, 2015, disponible en: http:// wmw. cemefi.org/esr/images/Guia\%20de\%20participacion\%20Distintivo\%20ESR\%20 2016\%20y\%20manual\%20del\%20sistema.pdf.

Chambers, C. y DAY, R., “The Banking Sector and CSR: An Unholy Alliance?”, Review Financial Regulation International, vol. 12, núm. 9, 2009.

ClavellinA-Miller, José Luis, "Crédito bancario y crecimiento económico en México”, Economía Informa, núm. 378, enero-febrero de 2013. 
COMISIÓn EuropeA, Corporate Social Responsibility (CSR), EC, 2011, disponible en: http://ec.europa.eu/enterprise/policies/sustainable-business/corporatesocial-responsibility/index_en.htm.

Comisión EuropeA, Documentos de la Unión Europea. Libros Verdes, EC, 2014, disponible en: http://ec.europa.eu/green-papers/index_es.htm.

Comisión Federal de Competencia Económica, Plan Estratégico 20142017, México, Cofece, 2015, disponible en: https://mmw.cofece.mx/cofece/ index.php.

COMISIÓN NACIONAL PARA LA PROTECCiÓn y DEFENSA DE LOS USUARIOS De Servicios Financieros, La Reforma Financiera es para ti, México, Condusef, 2015, disponible en: http://mmw.condusef.gob.mx/Revista/index.php/ usuario-inteligente/ condusef-responde/476-reforma-financiera-resultados.

DiARIO OFICIAL DE LA FEDERACIÓN, Decreto por el que se reforman, adicionan y derogan diversas disposiciones en materia financiera y se expide la Ley para Regular las Agrupaciones Financieras, México, Segob, 2014, disponible en: http:/ / wmw.dof. gob.mx $/$ nota_detalle.php?codigo $=5329408$ éfecha $=10 / 01 / 2014$.

Delgado-Sierra, Virgilio, Estudio del grado de desarrollo de la responsabilidad social corporativa través de las memorias de sostenibilidady de las audiencias en televisión. Tesis de doctorado, España, Universidad de la Rioja, 2012, disponible en: http:// biblioteca.universia.net/ html_bura/ficha/params/id/56506493.html.

De la Cuesta-GonzÁlez, Marta et al., "Analysis of Social Performance in the Spanish Financial Industry Through Public Data. A proposal”, Journal of Business Ethics, núm. 69, 2006.

Duque-Orozco, Yenni Viviana y Martínez-Barón, Deissy, "Responsabilidad Social Empresarial en la dimensión laboral: caso Bancolombia y BBVA", Revista Facultad de Ciencias Económicas: Investigación y Reflexión, Colombia, vol. XX, núm. 1, junio de 2012.

García-Cossío, Lourdes y PÉREZ-Ruiz, Andrea, "Responsabilidad social empresarial, estrategia y ventaja competitiva en el sector bancario español", Revista de Dirección y Administración de Empresas, España, núm. 21, diciembre de 2014.

INSTITUTO ETHOS, Indicadores Ethos de Responsabilidad Social Empresarial 2011, São Paulo, Instituto Ethos, 2011, disponible en: http:/ / wmw1.ethos.org.br/ EthosWeb/arquivo/0-A-bbe2011_Indic_ETHOS_ESP.pdf. 
InSTITUTO MEXICANO PARA LA COMPETITIVIDAD, La Reforma Financiera y los riesgos del crédito, México, Imco, 2013, disponible en: http:/ / imco.org.mx/ wp-content/ uploads/2013/09/LaReformaFinancierayLosRiesgosdelCredito.pdf.

INTERNATIONAL ORGANIZATION FOR STANDARIZATION, ISO 26000. Guía de Responsabilidad Social, España, IOS, 2010, disponible en: https:/ / wmw.iso. org/obp/ wi\#iso:std:iso:26000:ed-1:v1:es.

Ipsos PubliC AFFAIRS, Economia, RSE y Reputación Corporativa de las Empresas, IPSOS, 2010, disponible en: http:/ / wmw.ipsos.es/.

LEVY, Noemí, "Reforma financiera y Banca de Desarrollo: créditos o ilusiones”, Economía Informa, México, núm. 382, septiembre-octubre de 2013.

MARíN-GAVIRIA, María del Pilar et al., "Análisis empírico de la divulgación de información social en Chile: un estudio en empresas cotizadas", Revista Economía, Gestión y Desarrollo, Colombia, núm. 13, 2012, disponible en: http:/ / revistaeconomia.puj.edu.co/html/articulos/Numero_13/MALDONADO.pdf.

MORFín-MACIEL, Antonio, "Banca de desarrollo y el apoyo al acceso (México)", Serie Financiamiento del Desarrollo CEPAL, Santiago de Chile, núm. 208, 2005.

OlCESE-SANTONJA, Aldo et al., Manual de la empresa responsable y sostenible. Conceptos y herramientas de la responsabilidad social corporativa o de la empresa, España, McGraw-Hill, 2008.

ORGANIZACIÓN PARA LA COOPERACIÓN Y EL DESARROLlO ECONÓMiCO, Importancia de una conducta responsable para las empresas, OCDE, 2013, disponible en: https://mneguidelines.oecd.org/MNEguidelines_RBCmatters_ES.pdf.

PÉREZ-RuIZ, Andrea y RODRÍGUEZ DEL BOSQUE, Ignacio, "La imagen de responsabilidad social corporativa en un contexto de crisis económica: el caso del sector financiero en España", Universia Business Review, España, núm. 33, 2012.

RED DEL PACTO Mundial DE Y EN MÉxiCO A.C., Informe de actividades 2011, México, Red del Pacto Mundial de y en México, 2012, disponible en: bttp:/ / www.pactomundial.org.mx/home/ wp-content/ uploads/2011/03/InformePMM-2011-Draft-4.pdf.

RED DEL PACTO MUNDIAL DE Y EN MÉxiCO A.C., Informe de actividades 2012 y 2013, México, Red del Pactor Mundial de y en México 2014, disponi- 
Esta revista forma parte del acervo de la Biblioteca Jurídica Virtual del Instituto de Investigaciones Jurídicas de la UNAM

ble en: https://dl.dropboxusercontent.com/u/65975967/PMM/2014/Informe_2012_2013/IPMM2013_ok_FINAL.pdf.

Red del PaCto Mundial De y en México A.C., Informe de actividades 2014, México, Red del Pactor Mundial de y en México, 2015, disponible en: http://www.pactomundial.org.mx/home/wpcontent/ uploads/2015/04/Informe_final.pdf.

Red Del PaCto Mundial De y en México A.C., Informe de actividades 2016, México, Red del Pactor Mundial de y en México, 2016, disponible en: http:/ / files.constantcontact.com/ a1 af8da4201 / d3c64746-49f0-4331-bd7c88cb01ef2c37.pdf?ver=1481915386000.

RiverA, Eugenio y RodrígueZ, Adolfo, "Competencia y regulación en la banca de Centroamérica y México: un estudio comparativo”, Serie Estudios y perspectivas CEPAL, México, núm. 71, 2007.

RodríGueZ-NAva, Abigail y Dorantes-HernándeZ, Patricia Margarita, "La reciente reforma financiera en México: Transformaciones y perspectivas", Economía UNAM, México, vol. 13, núm. 37, 2016.

SECRETARía de HaCienda y CRÉdito PÚBlico, Comunicado de prensa 099, México, SHCP, 2016, disponible en: https://mwn.gob.mx/shcp/prensa/comunicado-de-prensa-099-2016.

StiglitZ, Joseph E. y Weiss, Andrew, "Credit Rationing in Markets with Imperfect Information”, American Economic Review, vol. 71, núm. 3, junio de 1981.

Turrent, Eduardo, Historia sintética de la Banca en México, México, Banco de México, 2007, disponible en: http://mmm.banxico.org.mx/sistema-financiero/ index.html $\# M R$.

VARGAS-SÁnCHEZ, Alfonso y VACA-ACOSTA, Rosa María, "Responsabilidad social corporativa y cooperativismo: vínculos y potencialidades", Revista de Economía Pública, Social y Cooperativa, España, núm. 53, noviembre de 2005.

Vergara-TAlamantes, Mario, "La reforma financiera y la banca de desarrollo: propuesta de un modelo de evaluación del desempeño de la Banca de Desarrollo Mexicana”, Revista Finanzas Públicas, vol. 8, núm. 19, 2015. disponible en: http:// wmm.cefp.gob.mx/publicaciones/revista/2015/rfpcefp0192015.pdf. 
Vives, Antonio y Peinado-VARA, Estrella (eds.), La responsabilidad social de la empresa en América Latina. Fondo multilateral de inversiones, Nueva York, Washington, Banco Interamericano de Desarrollo, 2011. (\$) 